\title{
Hepatic Gluconeogenic Fluxes and Glycogen Turnover during Fasting in Humans A Stable Isotope Study
}

\author{
M.K. Hellerstein, ${ }^{\star \ddagger}$ R.A. Neese, ${ }^{\star}{ }^{\ddagger}$ P. Linfoot, ${ }^{\star}$ M. Christiansen, ${ }^{\star}$ S. Turner, ${ }^{\ddagger}$ A. Letscher ${ }^{\ddagger}$ \\ *Division of Endocrinology and Metabolism, Department of Medicine, San Francisco General Hospital, University of California, San \\ Francisco, California 94110; and ${ }^{\ddagger}$ Department of Nutritional Sciences, University of California, Berkeley, California 94720 -3104
}

\section{Abstract}

Fluxes through intrahepatic glucose-producing metabolic pathways were measured in normal humans during overnight or prolonged $(60 \mathrm{~h})$ fasting. The glucuronate probe was used to measure the turnover and sources of hepatic UDP-glucose; mass isotopomer distribution analysis from $\left[2-{ }^{13} \mathrm{C}_{1}\right]$ glycerol for gluconeogenesis and UDP-gluconeogenesis; $\left[\mathrm{U}_{-}{ }^{13} \mathrm{C}_{6}\right.$ ] glucose for glucose production (GP) and the direct UDP-glucose pathway; and $\left[1-{ }^{2} \mathrm{H}_{1}\right]$ galactose for UDP-glucose flux and retention in hepatic glycogen. After overnight fasting, GP (fluxes in milligram per kilogram per minute) was $2.19 \pm 0.09$, of which 0.79 (36\%) was from gluconeogenesis, 1.40 was from glycogenolysis, 0.30 was retained in glycogen via UDP-gluconeogenesis, and 0.17 entered hepatic UDP-glucose by the direct pathway. Thus, total flux through the gluconeogenic pathway (1.09) represented 54\% of extrahepatic glucose disposal (2.02) and the net hepatic glycogen depletion rate was 0.93 (46\%). Prolonging $\left[2-{ }^{13} \mathrm{C}_{1}\right]$ glycerol infusion slowly increased measured fractional gluconeogenesis. In response to prolonged fasting, GP was lower $(1.43 \pm 0.06)$ and fractional and absolute gluconeogenesis were higher $(78 \pm 2 \%$ and $1.11 \pm 0.07$, respectively). The small but nonzero glycogen input to plasma glucose $(0.32 \pm 0.03)$ was completely balanced by retained UDPgluconeogenesis $(0.31 \pm 0.02)$. Total gluconeogenic pathway flux therefore accounted for $99 \pm 2 \%$ of GP, but with a glycogen cycle interposed. Prolonging isotope infusion to $10 \mathrm{~h}$ increased measured fractional gluconeogenesis and UDP-gluconeogenesis to 84-96\%, implying replacement of glycogen by gluconeogenic-labeled glucose. Moreover, after glucagon administration, GP (1.65), recovery of $\left[1-^{2} \mathrm{H}_{1}\right]$ galactose label in plasma glucose $(25 \%)$ and fractional gluconeogenesis (91\%) increased, such that $78 \%(0.45 / 0.59)$ of glycogen released was labeled (i.e., of recent gluconeogenic origin). In conclusion, hepatic gluconeogenic flux into glycogen and glycogen turnover persist during fasting in humans, reconciling inconsistencies in the literature and interposing another locus of control in the normal pathway of GP. ( $J$.

Address correspondence to Marc K. Hellerstein, M.D., Ph.D., Department of Nutritional Sciences, University of California, Berkeley, CA 94720-3104; or Division of Endocrinology and Metabolism, SF General Hospital, UC San Francisco, CA 94110. Phone: 510-6420646; FAX: 510-642-0535.

Received for publication 7 January 1997 and accepted in revised form 30 May 1997.

J. Clin. Invest.

(C) The American Society for Clinical Investigation, Inc. 0021-9738/97/09/1305/15 \$2.00

Volume 100, Number 5, September 1997, 1305-1319

http://www.jci.org
Clin. Invest. 1997. 100:1305-1319.) Key words: UDP-glucose - glucuronate probe - mass isotopomer distribution analysis (MIDA) • carbohydrate metabolism • substrate cycles

\section{Introduction}

Where does blood glucose come from in the postabsorptive state in normal humans? This important and seemingly straightforward metabolic question remains controversial (1$8)$. It is well known that the liver can produce glucose from the pathways of gluconeogenesis $(\mathrm{GNG})^{1}$ or glycogenolysis, and that the kidney might produce some glucose via GNG (9), but the relative contributions and the precise metabolic pathways traversed remain uncertain after many years of investigation.

Attempts to measure GNG directly with isotopes generally have concluded that GNG provides about $1 / 3$ of the roughly 2 $\mathrm{mg} / \mathrm{kg}$ per minute glucose produced in postabsorptive humans. Consoli et al. (2) reported $\sim 30 \%$ contribution from GNG, by using a ${ }^{14} \mathrm{C}$-acetate incorporation technique (10) that is now recognized to be flawed (11). Two recent ${ }^{2} \mathrm{H}_{2} \mathrm{O}$ incorporation techniques for measuring either phospho-enolpyruvate-derived or total GNG $(3,4)$ gave estimates of $32 \%$ and $47 \%$, respectively. Abstract reports $(5,6)$ using mass isotopomer distribution analysis (MIDA) reported $35-40 \%$ GNG contribution. These isotopic techniques all suggest a somewhat greater contribution from glycogenolysis than from GNG under postabsorptive conditions.

In contrast to isotopic results, studies by Shulman and coworkers (7) using in vivo nuclear magnetic resonance (NMR) spectroscopy of liver glycogen content combined with imaging of liver volume came to the opposite quantitative conclusion: net glycogen loss could account for only $36 \%$ of systemic glucose production (GP), the latter measured by isotope dilution. Thus, nonglycogen flux (assumed to represent GNG) was estimated by difference to contribute $64 \%$ of GP. Although previous direct measurements of liver glycogen content from serial liver biopsies performed by Nilsson et al. (1) $30 \mathrm{y}$ ago concluded that glycogen provides $2 / 3$ of GP, not $1 / 3$, Shulman and co-workers (7) proposed that incorrect estimation of liver volume and analytic problems might explain the difference from their NMR results.

Measurement of hepatic arteriovenous differences for GNG precursors has not resolved the issue. Barrett and Liu (8) concluded in a recent review that the sum of measured

1. Abbreviations used in this paper: $\mathrm{f}_{\mathrm{glc}}$, fractional contribution from GNG to plasma glucose; $f_{\text {glc }}$, fractional contribution from GNG to hepatic UDP-glc; glc, glucose; GlcUA, glucuronate; GNG, gluconeogenesis; GP, glucose production; M.E., molar excess; MIDA, mass isotopomer distribution analysis; M.P.E., molar percent excess; NMR, nuclear magnetic resonance; Ra, rate of appearance; Ra Glc, rate of appearance of plasma glucose; Ra UDP-glc, rate of appearance of hepatic UDP-glc. 
GNG precursors (lactate, alanine, and glycerol) taken up by the liver plus an estimate of intrahepatic amino acid catabolism could only account for, at most, $40 \%$ of GP in postabsorptive humans-incompatible with the $64 \%$ GNG estimated by NMR (7). Plasma glutamine was not included in their calculations and amino acid catabolism was estimated conservatively $(8,12)$. Nor do hepatic A-V differences exclude the possibility of renal GNG (9), which could reduce the contribution required from liver glycogen and account for the missing GNG precursors. Renal GNG should be apparent from isotopic measurements (depending upon the tracer used), however, and isotopic estimates have been in the $30-40 \%$ range (3-6), so postulating renal GNG does not reconcile the various results.

We hypothesized that some of these apparent contradictions might be due to an oversimplified model of fasting hepatic metabolism that does not take intracellular metabolic cycles into account. Fluxes through the hepatic GNG pathway may proceed into glycogen, rather than plasma glucose (1316), and glycogen deposition can occur at the same time as glycogen breakdown $(8,17,18)$. Studies in experimental animals have clearly shown that GNG flux can be directed into hepatic glycogen under the influence of exogenous glucose and insulin $(13,15,16)$. Moreover, the human liver also appears to be capable of autoregulation, in the face of large GNG precursor loads, whereby GNG flux is redirected into glycogen and/or glycogenolysis is suppressed to maintain stable GP rates (19, 20). Clore and Blackard (21) presented indirect evidence for glycogen synthesis from the GNG pathway in humans during prolonged fasting. If glyconeogenesis and glycogen turnover occur to a significant extent during fasting, the immediate contribution from glycogenolysis to GP would be greater than net glycogen loss. NMR spectroscopy of net glycogen balance would then give lower estimates of apparent glycogen input than isotopic techniques, and the immediate input from GNG into plasma glucose estimated by isotopic techniques would underestimate total flux through the GNG pathway, since a portion of GNG flux is deposited in liver glycogen. However, testing this model requires measurement of fluxes through the intrahepatic GNG pathway into glycogen as well as plasma glucose.

Our objectives in this study were to measure fluxes through glucose producing metabolic pathways in detail, including the role of gluconeogenic flux into glycogen and glycogen turnover, in the fasted state in humans using new noninvasive techniques. The techniques that we apply here are the glucuronate (GlcUA) probe for sampling the intrahepatic UDP-glc pool (16, 22-25); MIDA, for measuring fractional contributions from GNG to plasma glucose and hepatic UDP-glc $(16,26-$ $28)$; the intrahepatic dilution technique $(23,25,29)$ for measuring the rate of appearance (Ra) or turnover of hepatic UDP-glc; and techniques for estimating hepatic cycles, including glycogen synthesis-breakdown and glucose phosphorylationdephosphorylation $(16,23)$.

Portions of the material presented here have been previously reported in abstract form (6).

\section{Methods}

\section{Chemicals and isotopes}

$\left[\mathrm{U}-{ }^{13} \mathrm{C}_{6}\right]$ Glucose and $\left[2-{ }^{13} \mathrm{C}_{1}\right]$ glycerol were purchased from Isotec Inc. (Miamisburg, $\mathrm{OH}$ ). $\left[1{ }^{2} \mathrm{H}_{1}\right]$ galactose was purchased from Cambridge
Isotopes (Cambridge, MA). Isotopes were $>98 \%$ pure and $>99 \%$ enriched. For $\left[\mathrm{U}^{13} \mathrm{C}_{6}\right.$ ]glucose, the abundance of $\mathrm{M}_{6}$-glucose (i.e., all six carbons labeled with ${ }^{13} \mathrm{C}$ ) was $\sim 92-93 \%$ (see below). All chemicals were reagent grade.

\section{Human subjects and experimental protocols}

Normal human subjects were recruited by advertisement. Subjects with medical disorders, medications known to affect carbohydrate metabolism (glucocorticoids, thiazide diuretics, $\beta$-blockers or $\beta$-agonists, phenytoin, insulin, or oral hypoglycemic agents), obesity (body mass index $>28$ ), or a family history of non-insulin-dependent diabetes mellitus (NIDDM) in either parent were excluded. All protocols received previous approval from the UC San Francisco and UC Berkeley Committees on Human Research, and written informed consent was obtained before any procedures. Three different infusion protocols were performed in the General Clinical Research Center (GCRC) of San Francisco General Hospital (see Fig. 1). One protocol involved a standard overnight fast. Food and calorie-containing beverages were removed at 2000 of day 1 . Noncaloric, caffeine-free beverages were permitted during the night and next morning's infusion. Another protocol involved a $60-72 \mathrm{~h}$ fast. The fast occurred under supervision in the GCRC. Noncaloric, caffeine-free beverages were permitted. The short-infusion protocol (see Fig. $1 A$ ) was identical for the two fasting conditions. Infusion of $\left[\mathrm{U}-{ }^{13} \mathrm{C}_{6}\right]$ glucose $(0.02 \mathrm{mg} / \mathrm{kg}$ per minute), $\left[2-{ }^{13} \mathrm{C}_{1}\right]$ glycerol $(15 \mathrm{mg} / \mathrm{kg}$ lean body mass per hour), $\left[1-{ }^{2} \mathrm{H}_{1}\right]$ galactose $(0.08 \mathrm{mg} / \mathrm{kg}$ per minute $)$, and acetaminophen $(250 \mathrm{mg} / \mathrm{h})$ was begun at 0500 , with a 1 -h priming bolus followed by a $4-\mathrm{h}$ constant infusion. Hourly blood draws were taken from 0500 until $0800 \mathrm{~h}$, then at $0830,0840,0850$, and $0900 \mathrm{~h}$. Urine was collected at each void and aliquots were frozen. Of the 10 subjects who were studied after a 60-72-h fast, 5 had the complete isotopic paradigm performed (all three isotopes plus acetaminophen), while 5 did not receive $\left[1-{ }^{2} \mathrm{H}_{1}\right]-$ galactose and/or acetaminophen (they received only labeled glycerol and glucose). For the overnight-fasted protocol, 13 subjects received labeled glycerol and glucose; 10 of these subjects also received labeled galactose plus acetaminophen. In order to test predictions concerning the turnover of glycogen and its replacement by gluconeogenicallylabeled glucose units, prolonged infusions of $\left[2-{ }^{13} \mathrm{C}_{1}\right]$ glycerol were
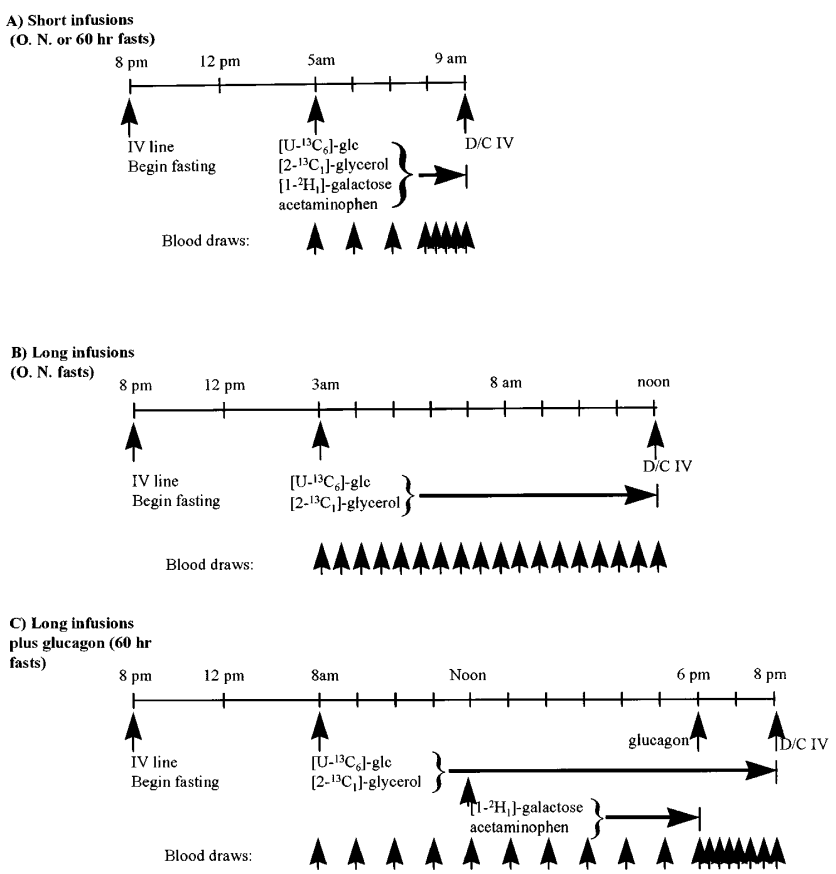

Figure 1. Infusion protocols used. O.N., overnight. 
<smiles>[2H]C1(O)OC(CO)C(O)C(O)C1O</smiles>

\section{Glucose}

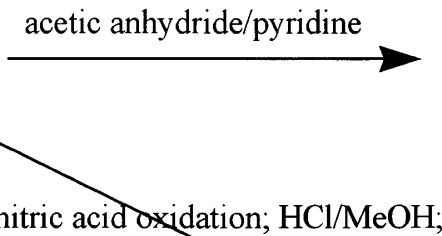

acetic anhydride/pyridine<smiles>[2H]C1(O)OC(C(=O)O)C(O)C(O)C1O</smiles>

nitric acid oxidation; $\mathrm{HCl} / \mathrm{MeOH}$ acetic anhydride/pyridine

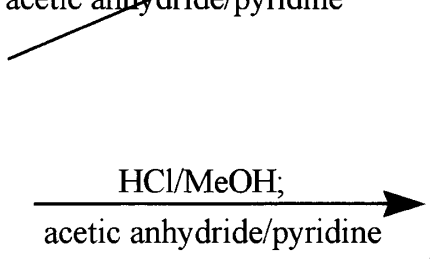<smiles>[2H]C(C)=O</smiles>

\section{Glucose}

pentaacetate

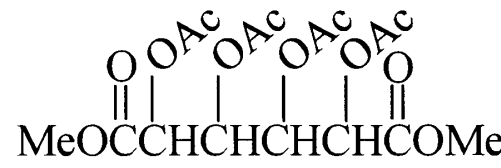

Saccharic acid MeOCCHCHCHCHCOMe tetraacetate<smiles>[2H]C(=O)OC1C(C(C)=O)OC([2H])(OC(C)=O)C(OC(C)=O)C1OC(C)=O</smiles>

\author{
Methyl \\ GlcUA \\ tetraacetate
}

\section{GlcUA}

Figure 2. Derivatives of glucose and GlcUA used. Fragments analyzed on the GC/MS are shown.

performed $(9 \mathrm{~h})$ at the end of an overnight fast (see Fig. $1 B, n=3$ subjects) or $(10 \mathrm{~h})$ at the end of a $60-72$-h fast (see Fig. $1 C, n=3$ subjects). In the subjects after prolonged fasting who received $10 \mathrm{~h}$ isotope infusions, we followed by administering glucagon and performing blood draws every $10 \mathrm{~min}$ for the subsequent $2 \mathrm{~h}$.

On the evening before infusions, intravenous lines were placed and a baseline blood draw was obtained. Intravenous solutions were infused by pump, with blood draws and urine collections as shown (see Fig. 1).

\section{Isolation of metabolites and preparation for mass spectrometry}

Glucose was isolated from deproteinized plasma by ion exchange chromatography as described elsewhere $(26,30)$. Glucose was analyzed as one of two derivatives (see Fig. 2), depending upon the mea- surement involved (see Table I). The glucose pentaacetate derivative was synthesized using acetic anhydride in pyridine (30). The saccharic acid derivatives of glucose and GlcUA were formed by oxidation with nitric acid, as described elsewhere (26). The methyl-tetraacetate derivative of GlcUA (see Fig. 2 and Table I) was formed by acetylation after methylation (26).

\section{Mass spectrometric analyses}

The gas chromatograph (GC) was a Hewlett-Packard 5890 type II (Hewlett-Packard, Palo Alto, CA), with a 60 m DB-17 Column (J\&W Scientific, Folsom, CA). The mass spectrometer (MS) was an HP 5971A (Hewlett-Packard). Glucose pentaacetate was analyzed by chemical ionization (C.I.) with methane under selected ion monitoring (S.I.M.) of $\mathrm{m} / \mathrm{z} 331-333$. Oven temperature program was $150^{\circ} \mathrm{C}$

Table I. Primary Measurements

\begin{tabular}{|c|c|c|}
\hline Parameter & Measurement & Analytic technique \\
\hline (1) Ra Glc & $\mathrm{M}_{6}$-Glc from $\left[\mathrm{U}_{-}{ }^{13} \mathrm{C}_{6}\right] \mathrm{Glc}$ & Saccharic or pentaacetate derivative of plasma glucose \\
\hline (2) RaUDP-glc & {$\left[1-{ }^{2} \mathrm{H}_{1}\right]$ GlcUA from $\left[1-{ }^{2} \mathrm{H}_{1}\right]$ Galactose } & $\begin{array}{l}\text { Methyl-tetraacetate derivative of GlcUA, corrected for underlying } \\
{ }^{13} \mathrm{C} \text { pattern in saccharic derivative of GlcUA }\end{array}$ \\
\hline (3) $f_{G l c}$ & $\mathrm{EM}_{2}$ and $\mathrm{EM}_{1}-\mathrm{Glc}$ from $\left[2-{ }^{13} \mathrm{C}_{1}\right]$ glycerol & Saccharic derivative of plasma glucose \\
\hline (4) $f_{\text {GlcuA }}$ & $\mathrm{EM}_{2}$ and $\mathrm{EM}_{1}-\mathrm{GlcU} A$ from $\left[2-{ }^{13} \mathrm{C}_{1}\right]$ glycerol & Saccharic derivative of GlcUA \\
\hline (5) $\mathrm{D}$ & $\mathrm{M}_{6}$-GlcUA from $\left[\mathrm{U}-{ }^{13} \mathrm{C}_{6}\right] \mathrm{Glc}$ & $\begin{array}{l}\text { Methyl-tetraacetate or saccharic derivative of GlcUA and } \mathrm{M}_{6} \text { of } \\
\text { glucose (see \#1 above) }\end{array}$ \\
\hline (6) $\mathrm{R}$ & {$\left[1-{ }^{2} \mathrm{H}_{1}\right]$ Glc from $\left[1-{ }^{2} \mathrm{H}_{1}\right]$ Galactose } & $\begin{array}{l}\text { Pentaacetate derivative of plasma glucose, corrected for underlying } \\
{ }^{13} \mathrm{C} \text { pattern in saccharic derivative of plasma glucose }\end{array}$ \\
\hline
\end{tabular}

$D$, fractional contribution from the direct glucose pathway to UDP-glucose; $R$, fractional recovery in blood glucose of infused labeled galactose. 

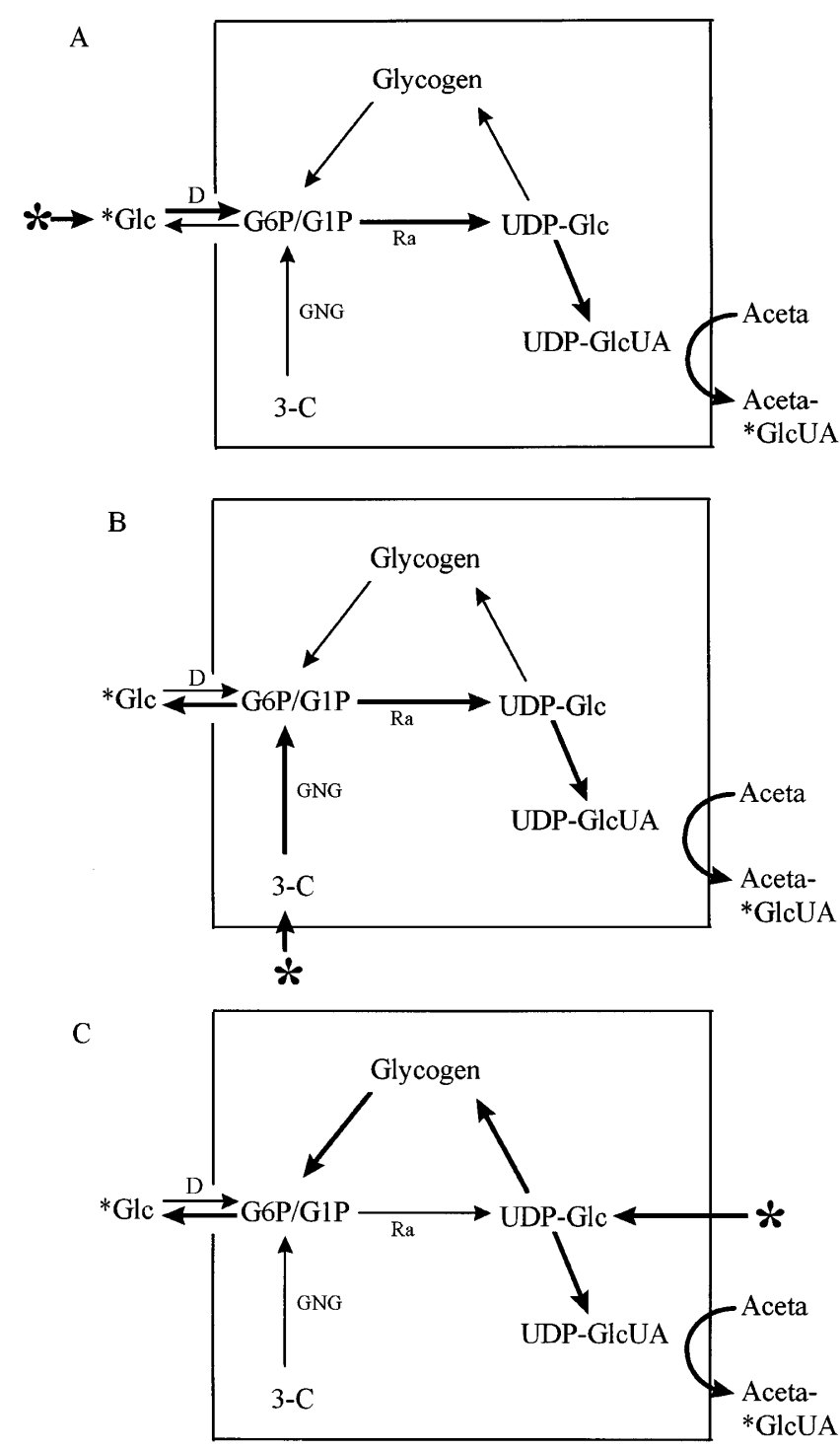

Figure 3. Hepatic pathways of $\mathrm{CHO}$ metabolism and isotopic paradigm for characterizing fluxes. Labeling is from three routes of input (bold asterisks) and two end-products are measured for isotope incorporation (Glc and GlcUA, nonbold asterisks). Bold lines indicate pathways measured from each isotope. $(A)$ Labeled glucose $\left(\mathrm{U}_{-}{ }^{13} \mathrm{C}_{6}\right)$, to measure Ra glucose and the direct pathway of UDP-glucose synthesis. $(B)$ Labeled glycerol $\left(2-{ }^{13} \mathrm{C}_{1}\right)$, to measure plasma $\mathrm{GNG}$ and hepatic UDP-GNG. $(C)$ Labeled galactose $\left(1-{ }^{2} \mathrm{H}_{1}\right)$, to measure RaUDP-glucose and escape of labeled UDP-glucose into plasma glucose. Aceta, acetaminophen.

with a rate of temperature rise at $40^{\circ} \mathrm{C} / \mathrm{min}$ until $270^{\circ} \mathrm{C}$. For the saccharic acid derivatives of glucose or GlcUA, m/z 347-349 were monitored and the temperature program was $40^{\circ} \mathrm{C} / \mathrm{min}$ until $240^{\circ} \mathrm{C}$ then $3^{\circ} \mathrm{C} / \mathrm{min}$ until $265^{\circ} \mathrm{C}$. For the methyl-tetraacetate derivative of GlcUA, m/z 317-319 were monitored and the $\left[1-{ }^{2} \mathrm{H}_{1}\right]$ enrichment was calculated by correction for underlying ${ }^{13} \mathrm{C}$ distribution (28). For the glucose pentaacetate derivative, the $\left[1-{ }^{2} \mathrm{H}_{1}\right]$ enrichment $(\mathrm{m} / \mathrm{z} 332)$ was also calculated by correction for underlying ${ }^{13} \mathrm{C}$ distribution (28).

\section{Metabolic model}

The liver is an open system with complex internal regulation. The system is characterized by exchanges of metabolites with the surround- ings (e.g., uptake of GNG precursors, release, or uptake of glucose) as well as by internal dynamics that are not communicated with the surroundings (e.g., channeling of GNG flux into glycogen; cycles of glycogen synthesis and breakdown). Fluxes of both types may turn out to be important in the control architecture of hepatic (and renal) carbohydrate metabolism. An isotopic paradigm for measuring a number of relevant parameters in vivo has been described and used previously in experimental animals (16), involving administration of three isotopic tracers with acetaminophen (see Fig. 3). Six primary measurements are made (see Table I) and several secondary parameters are then derived from these (see Table II).

\section{Primary measurements}

The general strategy (16) is to introduce distinguishable labels from all three potential routes of input (see Fig. $3, A-C$ ) into intracellular hexose-phosphate pools: $\left[\mathrm{U}_{-}{ }^{13} \mathrm{C}_{6}\right]$ glucose (see Fig. $3 \mathrm{~A}$ ), $\left[2-{ }^{13} \mathrm{C}_{1}\right]$ glycerol (see Fig. 3 B) and $\left[1-{ }^{2} \mathrm{H}_{1}\right]$ galactose (see Fig. $3 C$ ). Six primary measurements are made (see Table I), reflecting incorporation of these three labels into the two measurable end products of the system (plasma glucose and secreted GlcUA, the latter representing hepatic UDP-glc, see Fig. 3).

Rate of appearance of plasma glucose ( Ra Glc). Calculation of Ra Glc is from the dilution (12) of infused $\left[\mathrm{U}_{-}{ }^{13} \mathrm{C}_{6}\right.$ ] glucose in plasma $\mathrm{M}_{6}$ glucose (see Fig. $3 A$ and equation 1 in Table II). Because glucose might be produced by the kidneys as well as the liver (9), we refer to this flux as Ra Glc or GP, rather than hepatic GP. Calculation of Ra Glc after glucagon administration was by the standard nonsteady equations of Steele (31).

Rate of appearance of hepatic UDP-glc (Ra UDP-glc). Calculation of Ra UDP-glc is from the dilution of infused $\left[1{ }^{2} \mathrm{H}_{1}\right]$ galactose in $\mathrm{M}_{1}{ }^{-}$ GlcUA isolated from urinary acetaminophen-GlcUA (see Fig. 3 and equation 2 in Table II), as described previously by us $(22,26,29)$, and analogous to the radioisotopic method of Rother and Schwenk $(32,33)$.

\section{Fractional contribution from GNG to plasma glucose $\left(f_{\text {glc }}\right)$}

Calculation of $\mathrm{f}_{\mathrm{glc}}$ is by MIDA $(26,28,34)$ on plasma glucose, from $\left[2-{ }^{13} C_{1}\right]$ glycerol (see Fig. $3 B$ and equation 3 in Table II). This represents the fraction of plasma glucose that came from triose-p during the period of label administration.

Fractional contribution from GNG to hepatic UDP-glc $\left(f_{G l c U A}\right)$. Calculation of $\mathrm{f}_{\mathrm{GlcUA}}$ is by MIDA $(26,34)$ from $\left[2-{ }^{13} \mathrm{C}_{1}\right]$ glycerol, measured in GlcUA isolated from urinary acetaminophen-GlcUA (see Fig. $3 \mathrm{~B}$ and equation 4 in Table II). This represents the fraction of UDP-glc that came from triose-p during the period of label administration.

Fractional direct pathway contribution (D) from plasma glucose to hepatic UDP-glc. Calculation of the direct pathway contribution to UDP-glc is by the precursor-product relationship from $\mathrm{M}_{6}$-glucose to $\mathrm{M}_{6}$-GlcUA during infusions of $\left[\mathrm{U}-{ }^{13} \mathrm{C}_{6}\right]$ glucose $(22,25)$ (see Fig. 3 $A$ and equation 5 in Table II). This represents the fraction of UDPglc that was derived from the direct pathway during the isotope infusion period.

Fractional recovery of labeled hepatic UDP-glc in plasma glucose $(R)$. Calculation of labeled hepatic UDP-glc recovery in plasma glc is from the proportion of infused $\left[1-{ }^{2} \mathrm{H}_{1}\right]$ galactose that appears in plasma glucose (see Fig. $3 C$ and equation $6 A$ in Table II), on the assumption that infused galactose must pass through hepatic UDP-glc (the Leloir pathway, see Fig. 1) (23, 25). Alternatively, a related expression of this parameter is the proportion of plasma glucose that was derived from hepatic UDP-glc during the period of $\left[1-{ }^{2} \mathrm{H}_{1}\right]$ galactose administration (see equation $6 B$ in Table II). The latter calculation makes no assumptions about the specificity of labeled galactose uptake by the liver. Calculation of this parameter after glucagon administration does not require assumption of a steady state but represents at any moment the contribution of precursor (UDP-glc) to product (plasma glucose), as for any precursor-product method (34).

It should be noted that these measurements can be made concurrently without isotopic cross contamination. $\left[\mathrm{U}^{13} \mathrm{C}_{6}\right]$ glucose infused 


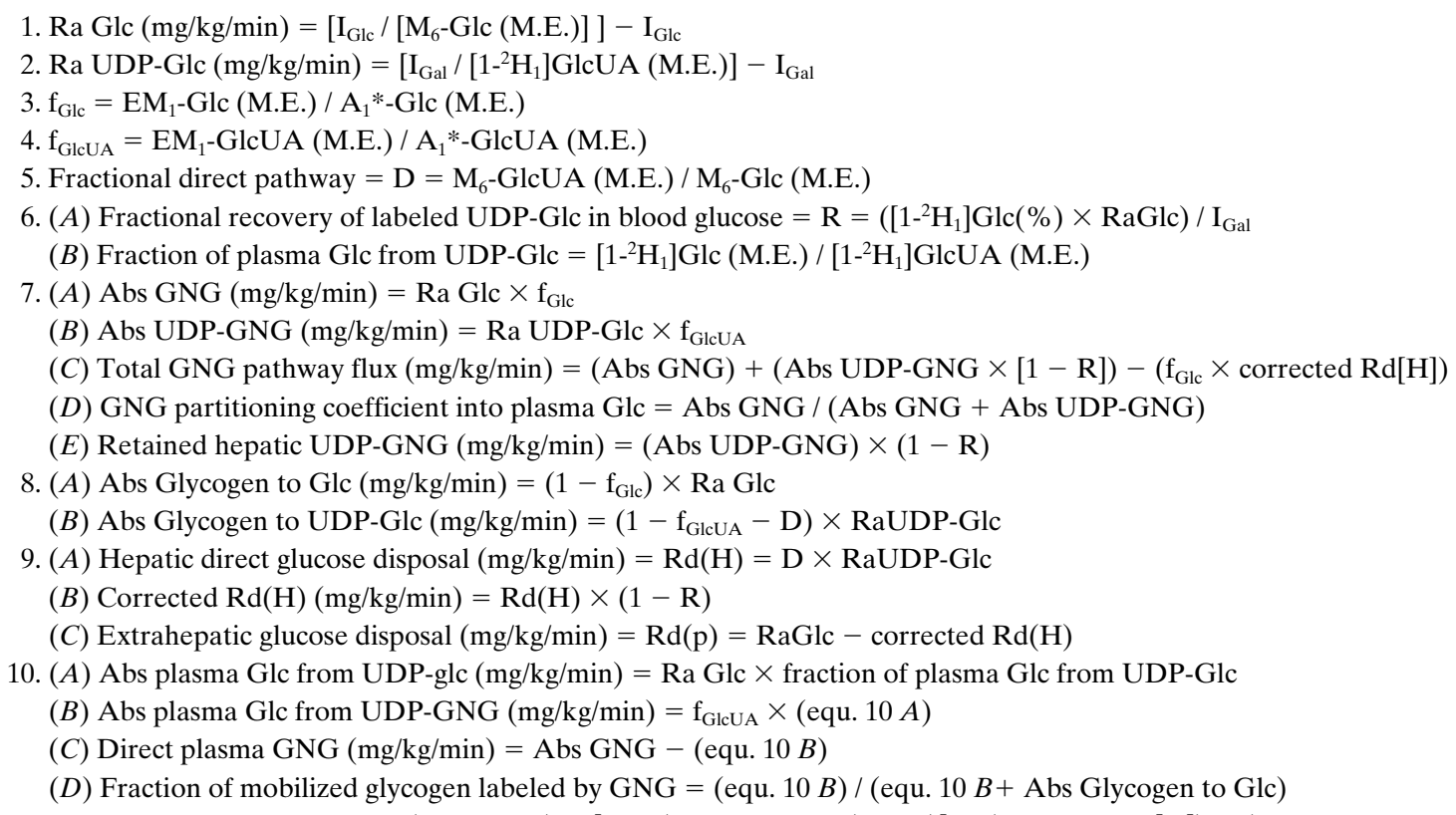

11. Net hepatic glycogen balance $(\mathrm{mg} / \mathrm{kg} / \mathrm{min})=[$ Abs $(\mathrm{UDP}-\mathrm{GNG} \times(1-\mathrm{R})]+($ corrected $\mathrm{Rd}[\mathrm{H}])-($ Abs Glycogen to Glc $)$

(A) Glucose / G6P cycling $(\mathrm{mg} / \mathrm{kg} / \mathrm{min})=\mathrm{GC}=\mathrm{RaGlc} \times(\mathrm{D} /[1-\mathrm{D}])$

(B) Total glucose output $(\mathrm{mg} / \mathrm{kg} / \mathrm{min})=\mathrm{TGO}=\mathrm{RaGlc}+\mathrm{GC}$

at the rates used here (to achieve 0.50-1.00 molar percent excess [M.P.E.] for $\mathrm{M}_{6}$-glucose in plasma) in humans results in no measurable contamination that could affect MIDA calculations of GNG (29). $M_{2}$-glucose is not elevated above baseline values and any $M_{1}$ glucose will be appropriately accounted for in GNG calculations. Also, the $\left[1-{ }^{2} \mathrm{H}_{1}\right]$ galactose label is removed in the saccharic derivative (see Fig. 2), thus does not affect GNG measurements. Finally, the underlying ${ }^{13} \mathrm{C}$-labeling pattern is corrected for by subtracting the enrichments in the saccharic derivative from enrichments in glucose pentaacetate or methyl GlcUA tetraacetate (see Fig. 2), through use of standard curves, when calculating labeling from $\left[1-{ }^{2} \mathrm{H}_{1}\right]$ galactose (our unpublished observations).

\section{Derived parameters}

Several useful parameters can then be derived $(16,23)$ by combining these primary measurements (see Table II).

Absolute fluxes through the GNG pathway. Absolute fluxes through GNG into plasma glucose or into hepatic UDP-glc are calculated as the fractional GNG contribution (f) times the Ra for each end-product (see equations $7 A$ and $B$ in Table II). Total flux through the GNG pathway (see equation $7 C$ in Table II) is calculated from the sum of absolute GNG plus absolute UDP-GNG, corrected for duplicated fluxes at the hexose-phosphate level (i.e., UDP-GNG that cycled to plasma glucose and plasma GNG-glucose that entered UDP-glc by the direct pathway), to avoid double accounting. To calculate partitioning of GNG flux between plasma glucose and hepatic UDP-glc, absolute GNG is compared to the sum of absolute UDP-GNG plus absolute GNG (see equation $7 \mathrm{D}$ in Table II).

Absolute fluxes from glycogenolysis. Calculation of glycogen to plasma glucose flux is by difference from GNG, i.e., $\left(1-\mathrm{f}_{\mathrm{glc}}\right) \times \mathrm{Ra}$ Glc (see equation $8 A$ in Table II). It should be noted that this represents the immediate contribution from glycogen to blood glucose (i.e., that which can be measured during the isotope infusion period), not the ultimate metabolic source of blood glucose or the net glyco- gen balance in the liver, if glycogen cycles are operating (see Fig. 3 and below). Flux from glycogenolysis can also contribute to UDP-glc, representing a glycogenolysis-glycogen resynthesis cycle. Because there are three possible sources of UDP-glc (the GNG pathway, the direct glucose pathway, and glycogenolysis; see Fig. 3), the glycogenolytic contribution to UDP-glc is calculated as the non-GNG, nondirect input, i.e., $\left(\left[1-\mathrm{f}_{\mathrm{GlcUA}}-\mathrm{D}\right] \times \mathrm{Ra}\right.$ UDP-glc) (see equation $8 B$ in Table II).

Flux from UDP-glc to plasma glucose (glycogen cycle). A useful derived parameter is the flux into plasma glucose from hepatic UDPglc. We assume in this calculation that UDP-glc passes through hepatic glycogen to enter plasma glucose, since the conversion of glucose-1-phosphate to UDP-glc is essentially irreversible, because of the very low cellular concentrations of pyrophosphate resulting from activity of inorganic pyrophosphatase (35). Accordingly, recovery of $\left[1-{ }^{2} \mathrm{H}_{1}\right]$ galactose-labeled UDP-glc in blood glucose represents release of newly synthesized glycogen into blood glucose (see Fig. 3 $C$ ). This parameter (see equation $10 \mathrm{~A}$ in Table II) is calculated by the precursor-product relationship between UDP-glc and plasma glucose when labeled $\left[1-^{2} \mathrm{H}_{1}\right]$ galactose is administered. In this case, $\left[1-{ }^{2} \mathrm{H}_{1}\right] \mathrm{UDP}$-glc is considered the precursor and plasma $\left[1-{ }^{2} \mathrm{H}_{1}\right] \mathrm{glu}-$ cose the product. The fraction of plasma glucose derived from UDPglc (see equation $6 B$ in Table II) is then multiplied times Ra Glc to calculate absolute UDP-glc to plasma glucose flux. The flux into plasma glucose that came specifically from the UDP-GNG pathway can then be calculated from the GNG contribution to UDP-glc (i.e., $\mathrm{f}_{\text {GlcuA }} \times$ equation $10 A$ [Table II]). By difference from absolute GNG, one can then calculate the absolute GNG flux into plasma glucose that did not pass through glycogen, but entered plasma glucose directly (direct GNG) (equation $7 A$ minus equation $10 B$ [Table II]). In this manner, one can also calculate the composition of glycogen that is being mobilized at any given time, by comparing the proportion that is unlabeled $\left(\left[1-\mathrm{f}_{\mathrm{Glc}}\right] \times \mathrm{Ra}\right.$ Glc, see equation $8 A$ in Table II) versus labeled via the GNG pathway (see equation $10 \mathrm{D}$ in Table 
II). Predictions concerning glycogen turnover and replacement during an infusion of a labeled GNG precursor can thereby be tested.

Disposal of plasma glucose into hepatic UDP-glc (Rd[H]). The direct entry of plasma glucose into hepatic UDP-glc is calculated from the fractional direct pathway contribution to UDP-glc times UDP-glc turnover, i.e., $\mathrm{D} \times \mathrm{Ra}$ UDP-glc (see equation $9 A$ in Table II). To use this as a measure of true disposal of the plasma glucose flux measured by dilution, one has to correct this value for the proportion of directly synthesized UDP-glc that returns to the plasma glucose pool. This recovery correction factor ( $R$, Table $\mathrm{I})$ is necessary because cycling of directly synthesized hepatic UDP-glc back to plasma glucose does not result in further dilution of plasma glucose, and thus does not add to measured Ra Glc (see equation 1 in Table II) and should not be subtracted from Ra Glc when calculating its disposal. This correction factor is measured from the recovery of $\left[1-^{2} \mathrm{H}_{1}\right]$ galactose in plasma glucose (see equation $6 \mathrm{~A}$ in Table II). Corrected disposal of plasma glucose into hepatic UDP-glc is then calculated from the fraction that is retained, i.e., $\operatorname{Rd}(\mathrm{H}) \times(1-\mathrm{R})$ (see equation $9 B$ in Table II). Extrahepatic or peripheral glucose disposal $(\mathrm{Rd}[\mathrm{p}])$ is then calculated as $\mathrm{Ra}$ Glc minus the corrected disposal rate of plasma glucose into hepatic UDP-glc (see equation $9 C$ in Table II).

Net glycogen balances. The absolute glycogen to glucose flux (see equation $8 A$ in Table II) overestimates the net glycogen contribution to plasma glucose flux (7) for two reasons. First, any GNG flux into glycogen that is retained by the liver (retained hepatic UDP-GNG, see equation $7 E$ in Table II) will reduce net negative glycogen balance; and, second, disposal of plasma glucose back into liver glycogen via the direct pathway (corrected $\mathrm{Rd}[\mathrm{H}]$, see equation $9 B$ in Table II) will also reduce net liver glycogen depletion. Accordingly, net negative or positive hepatic glycogen balance can be calculated from the sum of these two glycogen synthetic pathways minus absolute glycogen to glucose flux (see equation 11 in Table II).

Glucose-6-phosphate/plasma glucose cycling. Flux across glucose6-phosphatase exceeds GP by the rate of glucose cycling, or the phosphorylation/dephosphorylation cycle between plasma glucose and glucose-6-phosphate. Glucose cycling is estimated as described elsewhere $(15,23)$, as Ra Glc corrected for the direct pathway contribution to glucose-6-phosphate (see equation $12 A$ in Table II). Total glucose output (TGO) is then calculated as the sum of Ra Glc plus glucose cycling (see equation $12 \mathrm{~B}$ in Table II).

\section{Results}

Subjects fasted for 60-72 h $(n=10)$ will be presented first, as a validation of the approach, because the net gluconeogenic contribution to GP can be anticipated to be close to $100 \%$ under these conditions (i.e., net glycogen balance is expected to be

Table III. Prolonged Fasted Normal Subjects (4-h Isotope Infusions)

\begin{tabular}{|c|c|c|c|c|c|c|c|c|c|c|c|}
\hline Subject & $\mathrm{p}_{\text {Glc }}$ & \multicolumn{2}{|c|}{$\begin{array}{c}\mathrm{f}_{\mathrm{Glc}} \\
\text { (percentage) }\end{array}$} & Ra glc* & Abs GNG* & $\begin{array}{l}\text { Abs glyc } \\
\text { to glc* }\end{array}$ & \multicolumn{2}{|c|}{$\begin{array}{l}\text { Percentage Glc } \\
\text { from UDP-Glc }\end{array}$} & $\begin{array}{l}\text { Abs glc from } \\
\text { UDP-Glc* }\end{array}$ & $\begin{array}{l}\text { Abs glc from } \\
\text { UDP-GNG* }\end{array}$ & $\begin{array}{c}\text { Direct plasma } \\
\text { GNG* }\end{array}$ \\
\hline (1) & 0.136 & \multicolumn{2}{|c|}{77} & 1.21 & 0.93 & 0.28 & 19.2 & & 0.23 & 0.18 & 0.75 \\
\hline (1 B) & 0.138 & \multicolumn{2}{|c|}{65} & 1.44 & 0.94 & 0.50 & 13.2 & & - & - & - \\
\hline (2) & 0.124 & \multicolumn{2}{|c|}{89} & 1.77 & 1.57 & 0.24 & 7.9 & & 0.14 & 0.12 & 1.45 \\
\hline (2 B) & 0.129 & \multicolumn{2}{|c|}{85} & 1.47 & 1.26 & 0.21 & 18.0 & & - & - & - \\
\hline (3) & 0.119 & \multicolumn{2}{|c|}{75} & 1.50 & 1.13 & 0.37 & 19.3 & & 0.29 & 0.16 & 0.97 \\
\hline (4) & 0.146 & \multicolumn{2}{|c|}{69} & 1.39 & 0.97 & 0.42 & 16.4 & & 0.23 & 0.15 & 0.82 \\
\hline (5) & 0.114 & \multicolumn{2}{|c|}{78} & 1.65 & 1.29 & 0.35 & 15.8 & & 0.26 & 0.17 & 1.12 \\
\hline (6) & 0.153 & \multicolumn{2}{|c|}{70} & 1.12 & 0.79 & 0.33 & - & & - & - & - \\
\hline (7) & 0.095 & \multicolumn{2}{|c|}{81} & 1.32 & 1.07 & 0.25 & - & & - & - & - \\
\hline (8) & 0.112 & \multicolumn{2}{|c|}{83} & 1.39 & 1.15 & 0.24 & - & & - & - & - \\
\hline $\begin{array}{l}\text { Mean } \pm \mathrm{SEM}^{\ddagger} \\
(n)\end{array}$ & $\begin{array}{c}0.121 \pm .006 \\
\quad(10)\end{array}$ & \multicolumn{2}{|c|}{$\begin{array}{c}78 \pm 2 \\
(10)\end{array}$} & $\begin{array}{c}1.43 \pm .06 \\
(10)\end{array}$ & $\begin{array}{c}1.11 \pm .07 \\
(10)\end{array}$ & $\begin{array}{c}0.32 \pm .03 \\
\quad(10)\end{array}$ & $\begin{array}{c}16 \pm 2 \\
(7)\end{array}$ & & $\begin{array}{c}0.23 \pm .03 \\
(5)\end{array}$ & $\begin{array}{c}0.16 \pm .01 \\
(5)\end{array}$ & $\begin{array}{c}1.02 \pm .12 \\
(5)\end{array}$ \\
\hline Mean \pm SEM $^{\S}$ & $0.121 \pm .006$ & \multicolumn{2}{|c|}{$78 \pm 3$} & $1.50 \pm .10$ & $1.18 \pm .12$ & $0.32 \pm .04$ & $16 \pm 2$ & & $0.23 \pm .03$ & $0.16 \pm .01$ & $1.02 \pm .12$ \\
\hline Subject & $\mathrm{p}_{\mathrm{GleUA}}$ & $\begin{array}{c}\mathrm{f}_{\text {GlcuA }} \\
\text { (percentage) }\end{array}$ & $\begin{array}{c}\mathrm{Ra} \\
\text { UDP-Glc* }\end{array}$ & $\begin{array}{c}\text { Abs } \\
\text { UDP-GNG* }\end{array}$ & $\begin{array}{l}(1-\mathrm{R}) \times 100 \\
(\text { percentage })\end{array}$ & $\begin{array}{l}\text { Retained } \\
\text { UDP-GNG* }\end{array}$ & $\begin{array}{l}\text { Percentage } \\
\text { direct path }\end{array}$ & $\begin{array}{c}\text { Total } \\
\text { GNG flux* }\end{array}$ & $\begin{array}{c}\text { GNG } \\
\text { * } \\
\text { prop. RaGlc } \\
\text { (percentage) }\end{array}$ & $\begin{array}{c}\text { Net } \\
\text { glyc bal* }\end{array}$ & $\begin{array}{c}\text { Partition } \\
\text { GNG flux } \\
\text { (percentage Glc) }\end{array}$ \\
\hline (1) & 0.098 & 87.8 & 0.79 & 0.61 & 60.2 & 0.37 & - & 1.30 & 107 & +.09 & 60.3 \\
\hline (1 B) & - & - & 0.73 & - & 75.2 & - & - & - & - & - & - \\
\hline (2) & 0.093 & 99.4 & 0.50 & 0.44 & 70.2 & 0.31 & - & 1.88 & 106 & +0.11 & 78.1 \\
\hline (2 B) & - & - & - & - & 71.5 & - & - & - & - & - & - \\
\hline (3) & 0.122 & 77.0 & 0.61 & 0.41 & 57.5 & 0.23 & 3.3 & 1.36 & 91 & -.14 & 73.4 \\
\hline (4) & 0.128 & 73.9 & 0.76 & 0.50 & 65.1 & 0.33 & 10.6 & 1.30 & 93.5 & -.09 & 66.0 \\
\hline (5) & 0.182 & 74.2 & 0.79 & 0.51 & 60.6 & 0.31 & 5.0 & 1.60 & 97.0 & -.04 & 71.7 \\
\hline (6) & - & - & - & - & 70.9 & - & - & - & - & - & - \\
\hline (7) & - & 77.0 & - & - & - & - & - & - & - & - & - \\
\hline (8) & - & 85.0 & - & - & - & - & - & - & - & - & - \\
\hline $\begin{array}{l}\text { Mean } \pm \mathrm{SEM}^{\ddagger} \\
(n)\end{array}$ & $\begin{array}{c}0.121 \pm .010 \\
\quad(5)\end{array}$ & $\begin{array}{c}82.0 \pm 3.5 \\
(7)\end{array}$ & $\begin{array}{c}0.69 \pm .05 \\
(6)\end{array}$ & $\begin{array}{c}0.49 \pm .03 \\
(5)\end{array}$ & $\begin{array}{c}66.4 \pm 2.3 \\
(8)\end{array}$ & $\begin{array}{l}0.31 \pm .02 \\
\quad(5)\end{array}$ & $\begin{array}{c}6.3 \pm 2.2 \\
(3)\end{array}$ & $\begin{array}{c}1.49 \pm .11 \\
(5)\end{array}$ & $\begin{array}{c}99 \pm 2 \\
(5)\end{array}$ & $\begin{array}{c}-0.01 \pm .06 \\
(5)\end{array}$ & $\begin{array}{l}69.9 \pm 3.1 \\
\quad(5)\end{array}$ \\
\hline Mean \pm SEM $^{\S}$ & $0.121 \pm .010$ & $82.5 \pm 4.9$ & $0.69 \pm .06$ & $0.49 \pm .03$ & $62.7 \pm 2.2$ & $0.31 \pm .02$ & $6.3 \pm 2.2$ & $1.49 \pm .11$ & $99 \pm 2$ & $-0.01 \pm .06$ & $69.9 \pm 3.1$ \\
\hline
\end{tabular}

Abs, absolute; glyc, glycogen; glc, glucose; prop., proportion. Parameters calculated as described in the text. *milligrams per kilograms per minute. ${ }^{\ddagger}$ All subjects; ${ }^{\S}$ subjects with complete paradigm $(n=5)$. Subjects 1B and 2B, repeat studies of Subjects 1 and 2. 
zero after this duration of previous fasting). Results from overnight-fasted subjects will then be presented.

\section{Prolonged fasts}

4- $h$ isotope infusion protocol. With the 4-h isotope infusion protocol (Table III), Ra Glc was $1.43 \pm 0.06 \mathrm{mg} / \mathrm{kg}$ per minute and $\mathrm{f}_{\mathrm{glc}}$ was $78 \pm 2 \%$. Isotopic enrichments in $\mathrm{M}_{1^{-}}, \mathrm{M}_{2^{-}}$, and $\mathrm{M}_{6^{-}}$ glucose reached stable plateau values at relatively high enrichments (Fig. $4 A$ ), allowing highly reproducible calculations. The $\mathrm{M}_{6}$ enrichments were $1.35 \pm 0.16$ M.P.E. (mean $\pm \mathrm{SD}$ ), while $\mathrm{EM}_{1}$ was $0.1266 \pm 0.0163$ molar excess (M.E.) and $\mathrm{EM}_{2}$ was $0.0297 \pm 0.0050$ M.E. Absolute GNG was $1.11 \pm 0.07 \mathrm{mg} / \mathrm{kg}$ per minute and absolute glycogen to glc flux was not zero but was $0.32 \pm 0.03 \mathrm{mg} / \mathrm{kg}$ per minute. Ra UDP-glc was $0.69 \pm 0.06$ $\mathrm{mg} / \mathrm{kg}$ per minute $(n=5)$, which is lower than the value of $\sim 1.20 \mathrm{mg} / \mathrm{kg}$ per minute observed previously (23) in overnight fasted humans (see below). The value of $\mathrm{f}_{\mathrm{GlcUA}}$ was $82 \pm 4 \%$ $(n=7)$ and recovery of labeled UDP-glc in plasma glc was $33.6 \pm 2.3 \%$ (i.e., $66.4 \%$ of infused $\left[1{ }^{2} \mathrm{H}_{1}\right]$ galactose was retained in the liver, $1-R$ in Table III), so that retained intracellular gluconeogenic flux into glycogen was $0.31 \pm 0.02 \mathrm{mg} / \mathrm{kg}$ per minute $(0.69 \mathrm{mg} / \mathrm{kg}$ per minute $\times 82 \% \times 66 \%)$. The fraction of plasma glucose derived from UDP-glc was $17 \pm 2 \%$; plasma GNG flux that had passed through UDP-GNG was therefore $0.16 \pm 0.01 \mathrm{mg} / \mathrm{kg}$ per minute $(1.43 \mathrm{mg} / \mathrm{kg}$ per minute $\times 17 \% \times$ $82 \%$ ). In contrast, plasma GNG flux that did not pass through UDP-glc (direct GNG) was $1.02 \pm 0.12 \mathrm{mg} / \mathrm{kg}$ per minute (Table III). Total flux through the GNG pathway (plasma GNG plus retained UDP-GNG) was $1.49 \pm 0.11 \mathrm{mg} / \mathrm{kg}$ per minute $(n=5)$. This represented $99 \pm 2 \%$ of the Ra Glc measured in the same subjects.

In these subjects, the direct pathway contribution to UDP-

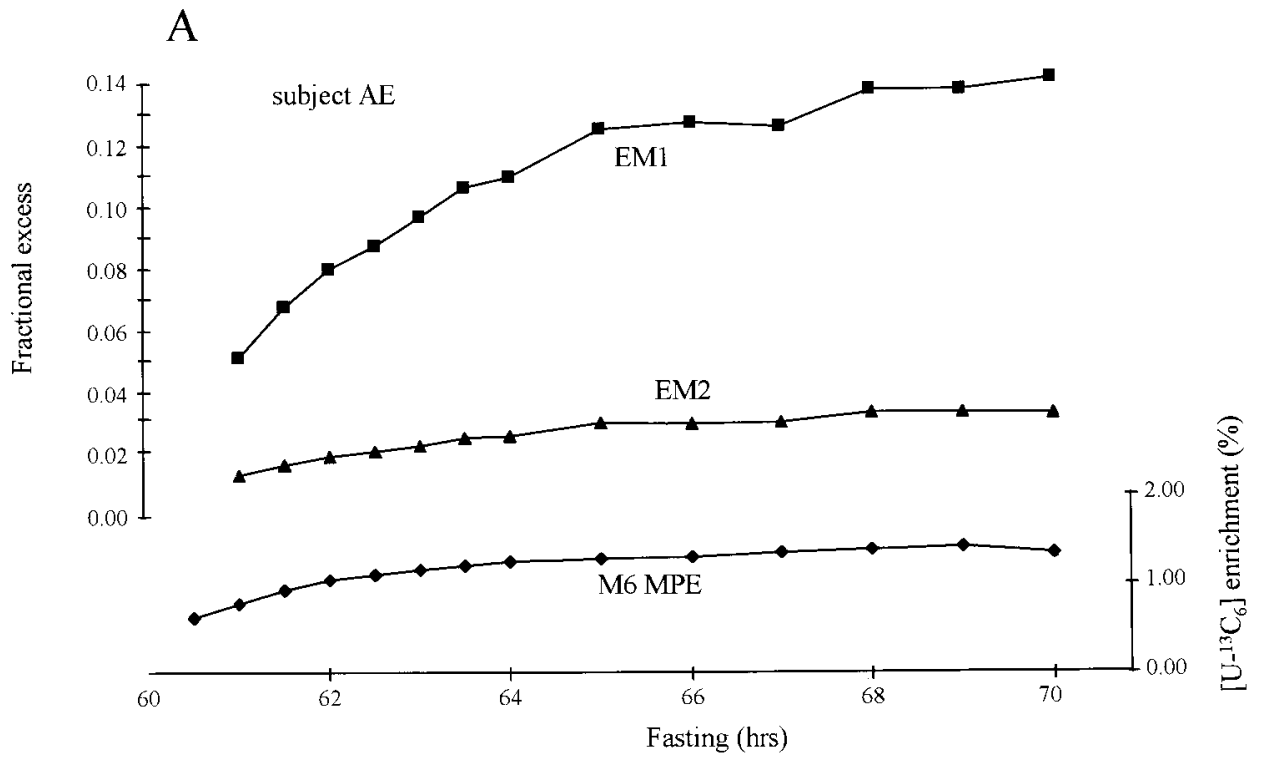

B
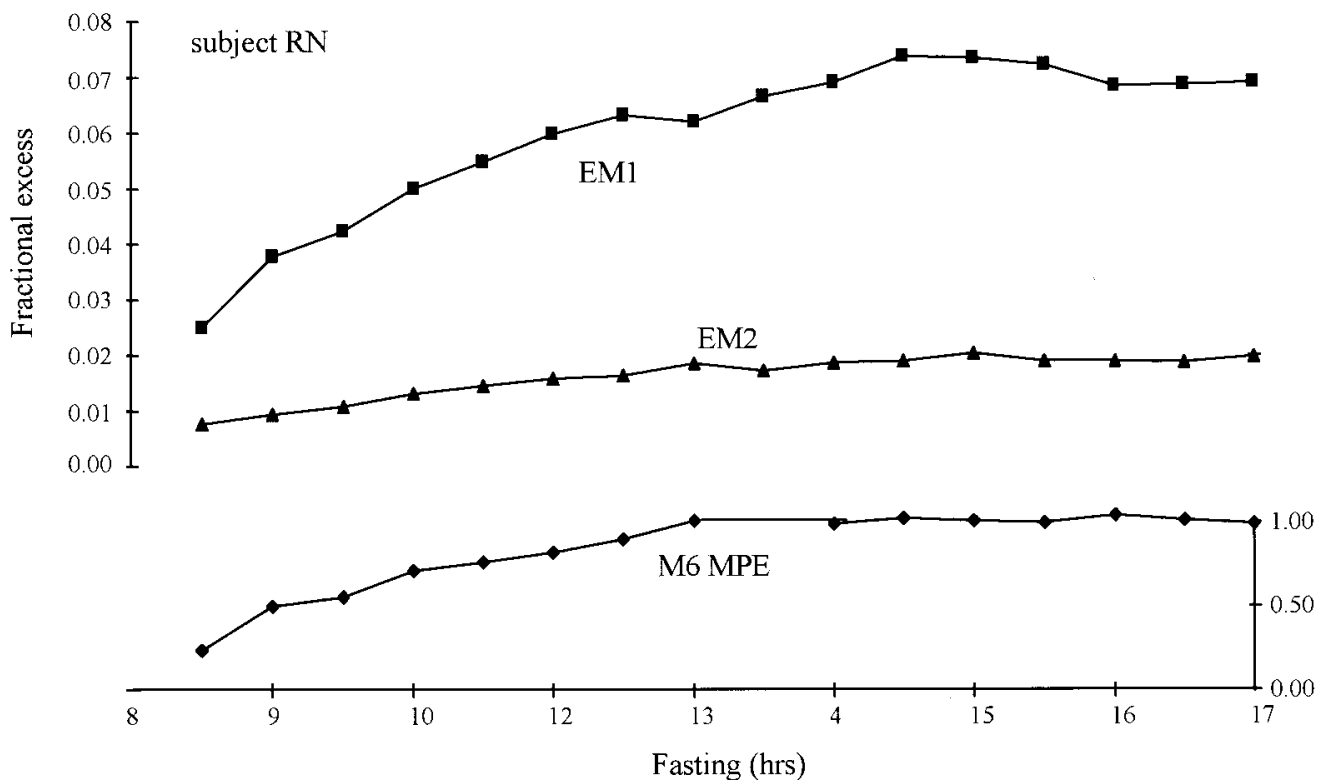

Figure 4. Steady state isotope enrichments achieved in plasma glucose (EM1, EM2, M6 $M P E)$. (A) A representative prolonged-fasted subject. $(B)$ A representative overnight-fasted subject. 

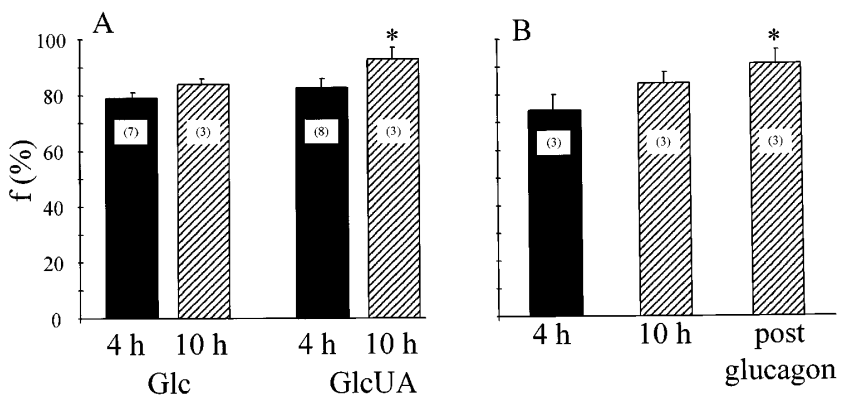

Figure 5. Effect of duration of isotope infusions $\left({ }^{13} \mathrm{C}\right.$-glycerol $)$ and of glucagon administration on $\mathrm{f}_{\mathrm{Glc}}$ and $\mathrm{f}_{\mathrm{GlcUA}} \cdot(A) \mathrm{f}_{\mathrm{Glc}}$ and $\mathrm{f}_{\mathrm{GlcUA}}$ compared in subjects receiving $4 \mathrm{~h}$ versus $10 \mathrm{~h}$ isotope infusions. $(B) \mathrm{f}_{\mathrm{Glc}}$ in subjects $(n=3)$ studied sequentially at $4,10 \mathrm{~h}$, and postglucagon. $* P<0.05$ versus $4 \mathrm{~h}$ value.

glc was extremely low $(6 \pm 4 \%$, or $0.03 \mathrm{mg} / \mathrm{kg}$ per minute) so that extrahepatic disposal of plasma glucose flux was essentially identical to Ra Glc. Net glycogen balance (calculated by subtracting the absolute glycogen to glucose flux from the glycogen synthesis by GNG and the direct pathway) was essentially zero $(-0.01 \pm 0.06 \mathrm{mg} / \mathrm{kg}$ per minute, Table III). Thus, total flux through the GNG pathway accounted for all GP and glucose used by tissues, although some of this GNG flux exchanged with unlabeled glucose units in glycogen, as part of a glycogen synthesis/mobilization cycle.

These results demonstrate that UDP-GNG nearly exactly balances mobilization of unlabeled glycogen after prolonged fasting, and that the finding of $\mathrm{f}_{\mathrm{Glc}}=78 \%$ and $\mathrm{f}_{\mathrm{GlcUA}}=82 \%$ (rather than 100\%) represents a physiologic glycogen synthesis/mobilization cycle rather than a methodologic artifact.

Prolonged isotope infusions. Next, we asked whether there is enough glycogen in the liver at the end of a 60-h fast to maintain unlabeled glucose output after $4 \mathrm{~h}$ of gluconeogenically labeled subunits entering glycogen. Glycogen turnover calculations ${ }^{2}$ suggest that hepatic glycogen should be between $50-75 \%$ replaced by gluconeogenically-labeled units after a 10-h infusion of $\left[2-{ }^{13} \mathrm{C}\right]$ glycerol. We tested this prediction of the glyconeogenesis/glycogen turnover model experimentally by performing prolonged $(10 \mathrm{~h})\left[2{ }^{-13} \mathrm{C}_{1}\right]$ glycerol infusions in subjects after a 60-h fast (Fig. 5 and Table IV). Between the 4th and 10th hours of label infusion, measured $\mathrm{f}_{\mathrm{Glc}}$ increased from 75 to $85 \%$ and unlabeled glycogen contribution to plasma glucose fell to $0.20 \pm 0.03 \mathrm{mg} / \mathrm{kg}$ per minute. The increase in $\mathrm{f}_{\mathrm{Glc}}$ could not be explained by slow entry of label into inaccessible triose-p precursor pools, because the value of $p$ for GNG did not change during the prolonged infusion (not shown). Sequential values were not taken for $\mathrm{f}_{\mathrm{GlcUA}}$, but the value after the 10 -h isotope infusion $(93.2 \pm 3.8 \%$, Table IV) was significantly higher than after the 4-h infusion (82.7 \pm $3.4 \%, P<0.05)$. Thus, for both GlcUA and glucose, results were consistent with the predicted $\sim 50 \%$ replacement of unlabeled glucose units in glycogen by GNG-labeled glucose units as the duration of isotope administration was prolonged.

Subsequent administration of glucagon. Next, we determined the isotope content of the glycogen units mobilized before and after glucagon administration in these subjects. Glucagon $(1 \mathrm{mg}$, iv) was administered to mobilize glycogen and directly measure its isotopic composition. During the first hour after glucagon administration, $\mathrm{Ra}$ Glc rose $\sim 43 \%$ from $1.23 \pm 0.10$ to $1.65 \pm 0.12 \mathrm{mg} / \mathrm{kg}$ per minute, then fell back to basal values within $90-120 \mathrm{~min}$ (Fig. 6). Values of $\mathrm{f}_{\text {glc }}$ peaked at $91 \pm 5 \%$ (Table IV). The absolute GNG rate, therefore, increased significantly, from $1.02 \pm 0.11$ to $1.51 \pm 0.19 \mathrm{mg} / \mathrm{kg}$ per minute, representing an increase of $0.49 \pm 0.12 \mathrm{mg} / \mathrm{kg}$ per minute. Recovery of $\left[1{ }^{2} \mathrm{H}_{1}\right]$ galactose in plasma glucose increased by $14 \pm 2$ to $31 \pm 4 \%(P<0.05$, Table IV, Fig. 6$)$, confirming the mobilization of prelabeled glycogen. Thus, the portion of mobilized glycogen that came from recently synthesized UDP-GNG was calculated to increase from $15 \pm 2$ to $28 \pm 4 \%$, or an increase of $0.28 \pm 0.02 \mathrm{mg} / \mathrm{kg}$ per minute (Table IV). Directly released GNG could then be calculated. This rose by $0.21 \pm 0.13 \mathrm{mg} / \mathrm{kg}$ per minute to $1.06 \pm 0.20 \mathrm{mg} / \mathrm{kg}$ per minute.

The unlabeled glycogen that was mobilized could be compared quantitatively to the GNG-labeled glucose units in glycogen that were mobilized. Before glucagon administration, labeled glucose from UDP-GNG was $0.18 \pm 0.01 \mathrm{mg} / \mathrm{kg}$ per minute while unlabeled glycogen was $0.20 \pm 0.05 \mathrm{mg} / \mathrm{kg}$ per minute, so that $48 \pm 8 \%$ of glycogen was labeled (Table IV). After glucagon, unlabeled glycogen input was nonsignificantly reduced $(0.14 \pm 0.03)$ whereas GNG-labeled glycogen increased to $0.45 \pm 0.02 \mathrm{mg} / \mathrm{kg}$ per minute, so that $78 \pm 7 \%$ of glycogen was GNG-labeled. Therefore, glycogen mobilized was between

\footnotetext{
2. If retained UDP-GNG in the liver is $0.31 \mathrm{mg} / \mathrm{kg}$ per minute in prolonged-fasted subjects (Table III), this equals about $1.25 \mathrm{~g} / \mathrm{h}$ or about $0.85 \mathrm{mg}$ per gram wet weight (gww) liver per hour (assuming liver weight to be $2 \%$ of body weight, or $1.5 \mathrm{~kg}$ ). After a prolonged fast, liver glycogen content stabilizes at $5-10 \mathrm{mg} / \mathrm{gww}(7,34)$ so that between $8-17 \%$ of stored hepatic glycogen should be replaced per hour by input from UDP-GNG. Thus, $\mathrm{k}_{\mathrm{s}} \cong 0.085-0.17 \mathrm{~h}^{-1}$ and $t_{1 / 2} \cong 4-9 \mathrm{~h}$ for replacement of glycogen by gluconeogenically-derived glucose units, if glycogen turnover is random (nonordered) under fasting conditions. After a $10 \mathrm{~h}$ infusion of $\left[2-{ }^{13} \mathrm{C}_{1}\right]$ glycerol, liver glycogen should be $50-75 \%$ replaced by GNG-derived glucose units.
}

Table IV. Effect of Glucagon Administration After a 60-h Fast and 10-h Isotope Infusion $(n=3)$

\begin{tabular}{|c|c|c|c|c|c|c|c|c|c|c|c|}
\hline & $\mathrm{Gp}^{*}$ & $\begin{array}{c}\mathrm{f}_{\mathrm{glc}} \\
\text { (percentage) }\end{array}$ & $\begin{array}{l}\text { Total } \\
\text { GNG* }\end{array}$ & $\begin{array}{l}\text { Percentage } \\
\text { Glc from } \\
\text { UDP-Glc }\end{array}$ & $\begin{array}{c}\mathrm{f}_{\mathrm{GlcUA}} \\
\text { (percentage) }\end{array}$ & $\begin{array}{l}\text { Percentage } \\
\text { Glc from } \\
\text { UDP-GNG }\end{array}$ & $\begin{array}{c}\text { Abs Glc } \\
\text { from } \\
\text { UDP-GNG* }\end{array}$ & $\begin{array}{l}\text { Direct } \\
\text { plasma } \\
\text { GNG* }\end{array}$ & $\begin{array}{l}\text { Unlabeled } \\
\text { glycogen* }\end{array}$ & $\begin{array}{l}\text { Sum unlabeled } \\
\text { plus labeled } \\
\text { glycogen* }\end{array}$ & $\begin{array}{c}\text { Percentage } \\
\text { glycogen } \\
\text { labeled }\end{array}$ \\
\hline Before glucagon & $1.23 \pm .10$ & $84 \pm 4$ & $1.02 \pm .11$ & $17 \pm 3$ & $93 \pm 4$ & $15 \pm 2$ & $0.18 \pm .01$ & $0.85 \pm .10$ & $0.20 \pm .05$ & $0.38 \pm .04$ & $48 \pm 8$ \\
\hline After glucagon & $1.65 \pm .12^{\ddagger}$ & $91 \pm 5$ & $1.51 \pm .19^{\ddagger}$ & $31 \pm 4^{\ddagger}$ & N.D. & $28 \pm 4^{\ddagger}$ & $0.45 \pm .02^{\ddagger}$ & $1.06 \pm .20$ & $0.14 \pm .03$ & $0.59 \pm .08^{\ddagger}$ & $78 \pm 7^{\ddagger}$ \\
\hline Change & $0.43 \pm .04$ & $7 \pm 6$ & $0.49 \pm .12$ & $14 \pm 2$ & - & $13 \pm 2 \%$ & $0.28 \pm .02$ & $0.21 \pm .13$ & $-0.06 \pm .09$ & $0.21 \pm .10$ & $28 \pm 10$ \\
\hline
\end{tabular}

Mean \pm SEM are shown. ${ }^{\ddagger} P<0.05$ compared to pre-glucagon value. N.D., not done. *milligrams per kilograms per minute. 


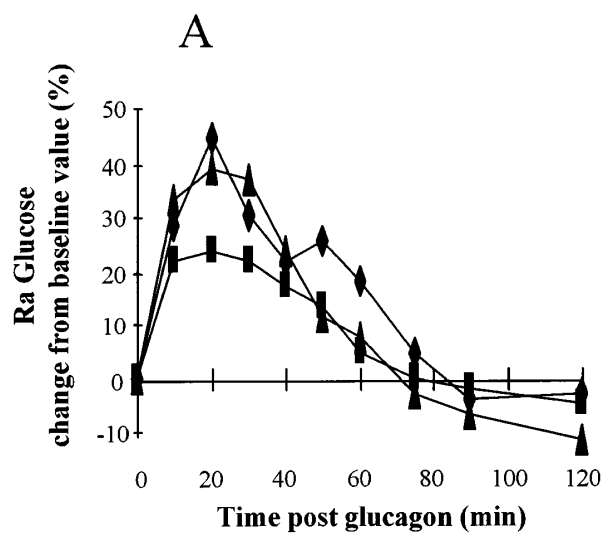

half to three-quarters replaced with GNG-labeled glucose units after $10 \mathrm{~h}$ of isotope administration, consistent with predicted replacement kinetics and the observed rise in $\mathrm{f}_{\mathrm{Glc}}$ and $\mathrm{f}_{\text {GlcUA }}$ (Fig. 5). The results also suggest that glucagon preferentially mobilized recently synthesized glycogen.

\section{Overnight fasting}

Subjects $(n=13)$ in the postabsorptive state were also studied by this approach. Isotopic enrichments reached stable plateaus

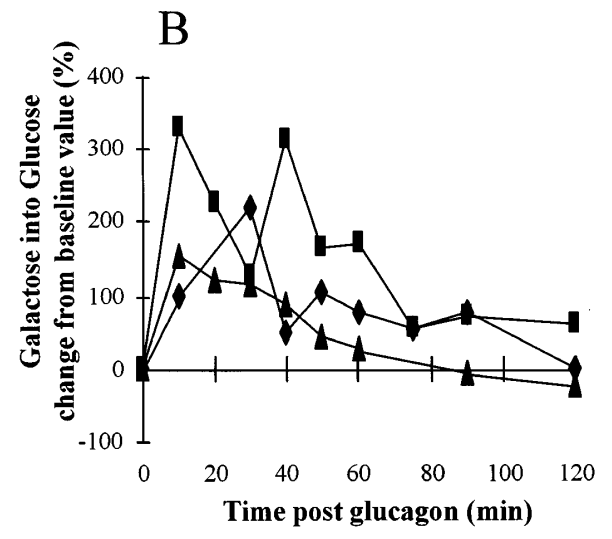

Figure 6. Effect of glucagon on $(A)$ Ra Glc, and $(B)\left[1-{ }^{2} \mathrm{H}_{1}\right]$ galactose recovery in plasma glucose in $60-\mathrm{h}$ fasted subjects.

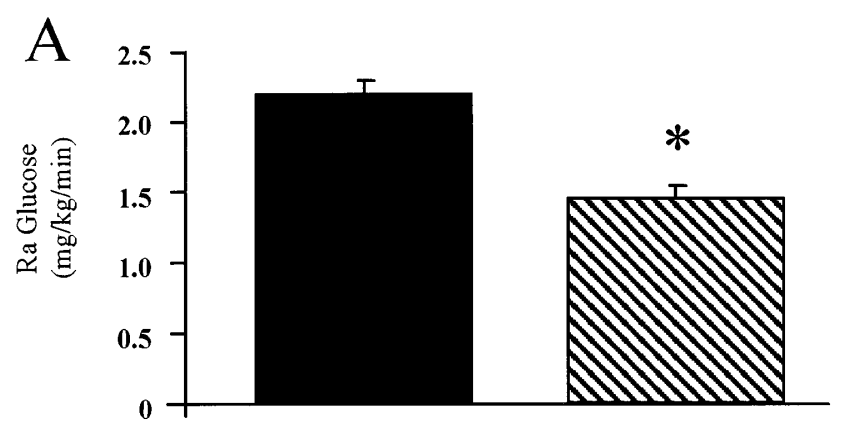

at relatively high values, with $\mathrm{M}_{6}$ enrichments of $0.94 \pm$ 0.10 M.P.E. (mean \pm SD), $\mathrm{EM}_{1} 0.0539 \pm 0.0100$ M.E. and $\mathrm{EM}_{2}$ $0.0127 \pm 0.034$ M.E. (Fig. 4 B). In comparison to prolonged fasts while using the same 4-h infusion protocol (Figs. 7-9), Ra Glc was higher in overnight fasts $(2.19 \pm 0.09$ versus $1.46 \pm 0.08$ $\mathrm{mg} / \mathrm{kg}$ per minute, $P<0.01)$; $\mathrm{f}_{\mathrm{Glc}}(36 \pm 3$ versus $78 \pm 2 \%, P<$ $0.01)$ and $\mathrm{f}_{\mathrm{GlcUA}}(32 \pm 5$ versus $82 \pm 4 \%, P<0.01)$ were lower; absolute plasma GNG was somewhat lower $(0.79 \pm 0.20$ versus $1.11 \pm 0.07 \mathrm{mg} / \mathrm{kg}$ per minute, $P<0.05)$; Ra UDP-glc was
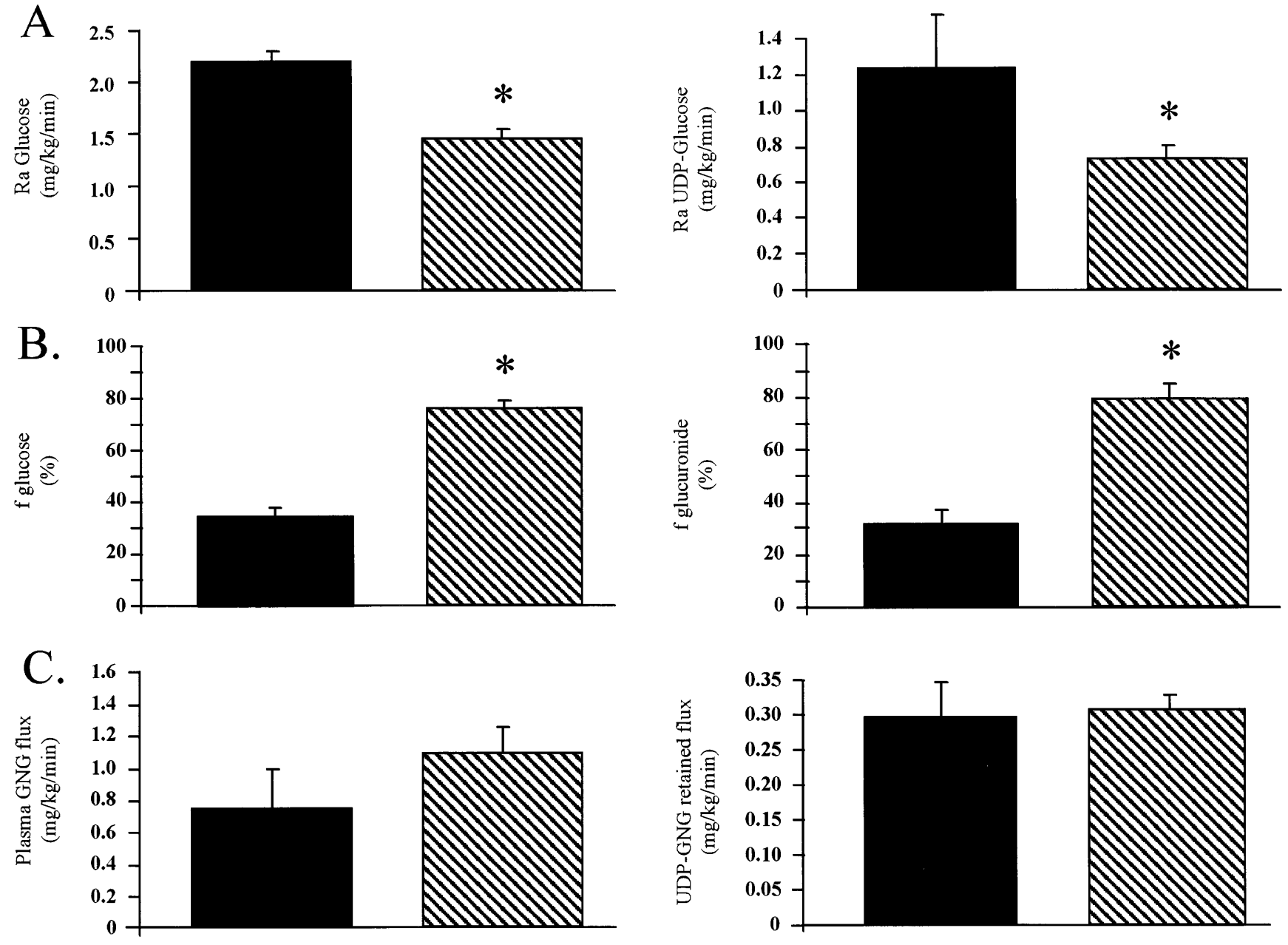

Figure 7. Comparison of GNG fluxes in 11 -h fasted and 60 -h fasted subjects. ${ }^{*} P<0.05$ versus 11 -h fasted subjects. $(A)$ Ra glucose $(l e f t)$ and Ra UDP-glc (right); $(B) \mathrm{f}_{\mathrm{Glc}}($ left $)$ and $\mathrm{f}_{\mathrm{GlcUA}}($ right $)$; and $(C)$ plasma GNG flux (left) and retained UDP-GNG flux $($ right $)$. 
A

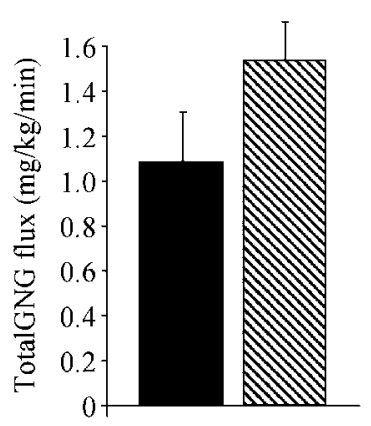

B

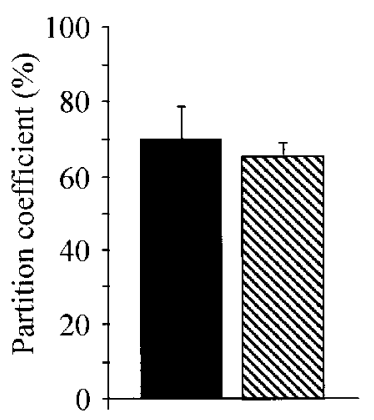

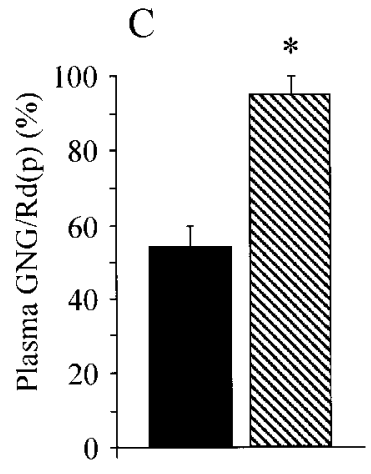

Figure 8. Total flux through GNG pathway and related parameters in 11 -h versus $60-\mathrm{h}$ fasted subjects. $* P<0.05$ versus 11 -h fasted subjects. $(A)$ Total GNG pathway flux (sum of plasma GNG and retained UDP-GNG); $(B)$ partitioning coefficient for GNG pathway fluxes (percentage into plasma glucose); $(C)$ Total GNG pathway flux as percent of glucose $\operatorname{Rd}(p)$. higher $(1.24 \pm 0.29$ versus $0.74 \pm 0.05 \mathrm{mg} / \mathrm{kg}$ per minute, $P<$ $0.05)$; absolute UDP-GNG was not significantly different $(0.40 \pm 0.05$ versus $0.49 \pm 0.03 \mathrm{mg} / \mathrm{kg}$ per minute $)$; the direct pathway contribution to UDP-glc was higher (18 \pm 4 versus $6 \pm 4 \%, P<0.05)$ and retained direct pathway input was higher $(0.17 \pm 0.02$ versus $0.03 \pm 0.01 \mathrm{mg} / \mathrm{kg}$ per minute, $P<0.01)$. The recovery of labeled UDP-glc in plasma glucose was lower in postabsorptive subjects ( $24 \pm 5$ versus $34 \pm 2 \%$ ), and absolute flux from UDP-GNG into glucose was not significantly different $(0.27 \pm 0.08$ versus $0.18 \pm 0.02 \mathrm{mg} / \mathrm{kg}$ per minute $)$.

Of interest here were the calculated net glycogen balances and total GNG pathway fluxes, for comparison to NMR spectroscopic results (7). Total GNG flux was $1.09 \pm 0.08 \mathrm{mg} / \mathrm{kg}$ per minute (Fig. 8) while net glycogen balance was $-0.93 \pm 0.07$ $\mathrm{mg} / \mathrm{kg}$ per minute (Fig. 9) in postabsorptive subjects. Total GNG pathway flux was therefore less than the $1.49 \pm 0.11 \mathrm{mg} / \mathrm{kg}$ per minute value in prolonged fasting (Fig. 8), but still accounted for $54 \pm 8 \%$ of extrahepatic glucose disposal $(2.02 \mathrm{mg} /$ $\mathrm{kg}$ per minute). Put differently, the apparent $\mathrm{f}_{\text {Glc }}$ value of $\sim 36 \%$ $(0.79 \mathrm{mg} / \mathrm{kg}$ per minute) after a 4 -h isotope infusion (Fig. 7) does not mean that net glycogen depletion occurs at a rate $64 \%(1.40 \mathrm{mg} / \mathrm{kg}$ per minute) of systemic glucose flux (2.19 $\mathrm{mg} / \mathrm{kg}$ per minute). Instead, the glycogen replaced via UDPGNG $(0.30 \pm 0.05 \mathrm{mg} / \mathrm{kg}$ per minute, Fig. 7) represents net GNG pathway flux, while plasma glucose that returned by the direct pathway to liver glycogen $(0.17 \mathrm{mg} / \mathrm{kg}$ per minute $)$ further reduced net glycogen depletion. Net glycogen depletion was therefore $0.93 / 2.02=46 \%$ of tissue glucose use or 0.93 / $2.19=42 \%$ of GP (Fig. 9).

Glycogen turnover and effect of prolonged $\left[2{ }^{13} C_{1}\right]$ glycerol infusions on GNG in ON fasted subjects. Expected glycogen replacement by UDP-GNG-derived glucose units can also be calculated in $\mathrm{ON}$ fasted subjects, to estimate the effects of in- creasing the duration of isotope infusion. Measured $\mathrm{f}_{\mathrm{Glc}}$ should increase slowly but progressively during a prolonged infusion of labeled glycerol as GNG-labeled glucose units start to be mobilized from glycogen. ${ }^{3}$ To test this prediction, a subset of subjects $(n=3)$ received $\left[2-{ }^{13} \mathrm{C}_{1}\right]$ glycerol for an extra $5 \mathrm{~h}$ in the postabsorptive state (total infusion time of $9 \mathrm{~h}$ ). The value for $\mathrm{f}_{\mathrm{Glc}}$ increased progressively (Fig. 10) in all subjects studied. No change in p (Fig. 10) was observed, arguing against the possibility that the increasing $\mathrm{f}$ was due to slow entry of labeled glycerol into relatively inaccessible hepatic precursor pools.

\section{Other parameters}

The partitioning coefficient for GNG flux can be estimated from GNG flux into plasma Glc relative to UDP-glc (Fig. 11). Partitioning of GNG flux may reflect activities of glucose6-phosphatase and/or glycogen synthase (13-16). Under both fasting conditions studied here, about $2 / 3$ of GNG flux entered plasma glucose $(69.9 \pm 3.1 \%$ in prolonged fasted, $66.4 \pm 1.5$ in overnight fasted). These values are similar to results in 24h-fasted rats $(15,27)$.

Various intrahepatic cycles were also estimated (Fig. 12). The glucose $/ \mathrm{G} \mathrm{P}^{\prime}$ ase cycle was $0.44 \pm 0.06$ in overnight-fasted and $0.10 \pm 0.03 \mathrm{mg} / \mathrm{kg}$ per minute in prolonged-fasted subjects. UDP-glc to plasma Glc flux (one component of the glycogen

3. If retained UDP-GNG in the liver was $0.30 \mathrm{mg} / \mathrm{kg}$ per minute in overnight fasted subjects (Fig. 7), this represents $1.25 \mathrm{~g} / \mathrm{h} \cong 0.85 \mathrm{mg} /$ gww liver per hour. If glycogen content in postabsorptive liver is $30-40 \mathrm{mg}$ per gram wet weight, then the glycogen replacement rate by UDP-GNG is about $2.5 \% / \mathrm{h}\left(0.025 \mathrm{~h}^{-1}\right)$. The $t_{1 / 2}$ of glycogen replacement should be about 25-30 h and, after a 9-h infusion of [2${ }^{13} \mathrm{C}_{1}$ ]glycerol, liver glycogen should be $15-20 \%$ replaced by GNGderived glucose units.
A

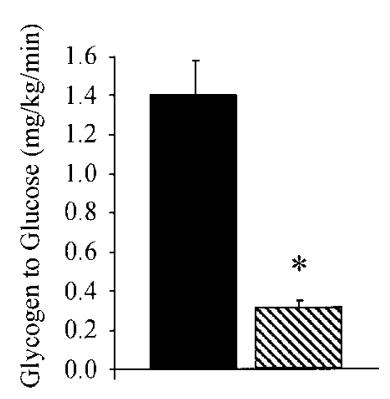

B

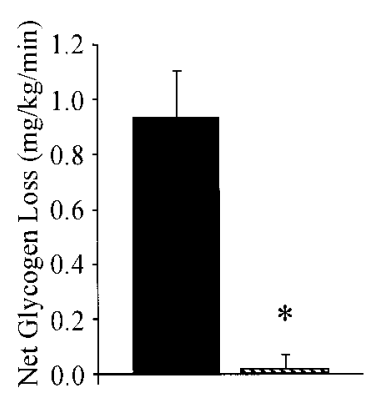

C

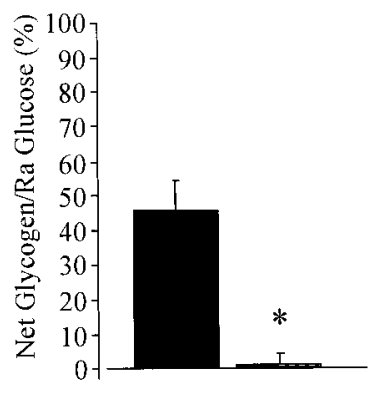

Figure 9. Fluxes from liver glycogen to plasma glucose, in 11-h versus 60 -h fasted subjects $* P<0.05$ versus 11 -h fasted subjects. $(A)$ Contribution of glycogen to glucose; $(B)$ net glycogen depletion; $(C)$ Net glycogen depletion as percent of glucose $\mathrm{Rd}$. 


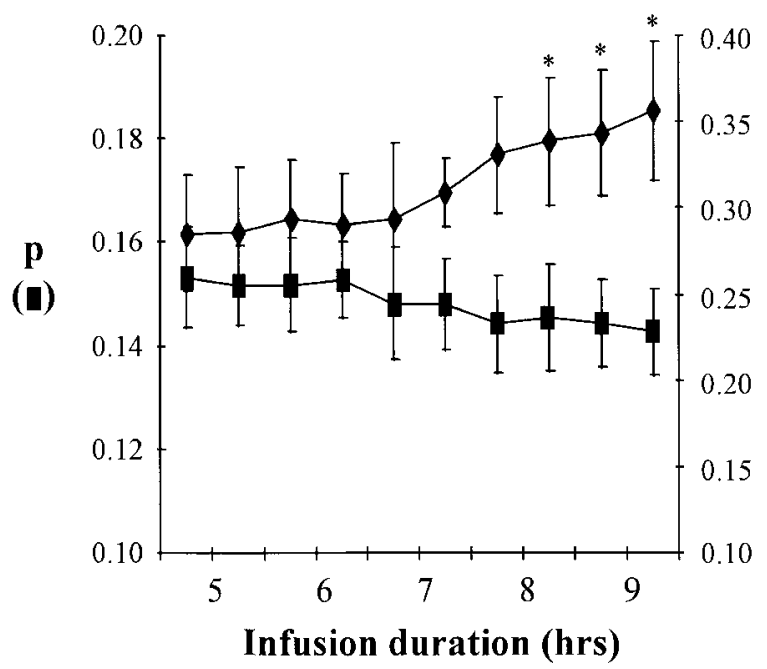

Figure 10. Effect of prolonged infusions of $\left[2-{ }^{13} \mathrm{C}_{1}\right]$ glycerol on $\mathrm{f}_{\mathrm{Glc}}$ and $\mathrm{p}$ in 11 -h fasted subjects. $* P<0.05$ versus $4-5 \mathrm{~h}$ values.

synthesis/breakdown cycle) was $0.27 \pm 0.08$ and $0.24 \pm 0.02 \mathrm{mg} / \mathrm{kg}$ per minute, in overnight- and prolonged-fasted subjects, respectively. The cycle from glycogen back to UDP-glc (another aspect of the glycogen synthesis/breakdown cycle) was also more active at 0.64 versus $0.10 \mathrm{mg} / \mathrm{kg}$ per minute in overnightfasted versus prolonged-fasted subjects. A schematic model of the rates of these intracellular (presumably intrahepatic) cycles is shown in postabsorptive and prolonged-fasted states
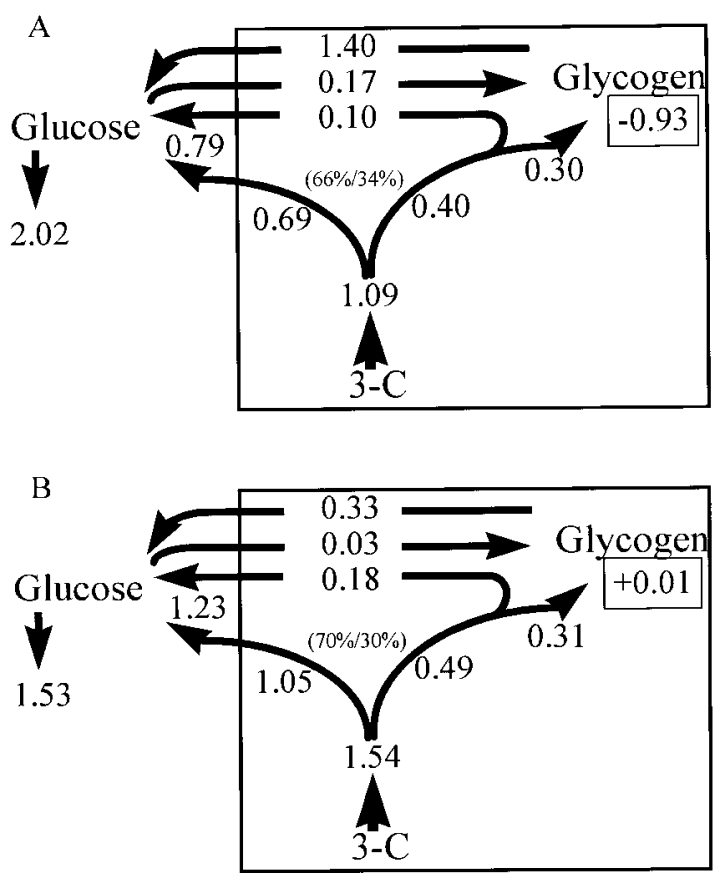

Figure 11. Schematic model of hepatic pathway fluxes. Numbers represent absolute fluxes through unidirectional pathway indicated. Percentages represent partitioning coefficient for GNG fluxes. Bracketed positive or negative value near glycogen represents net glycogen balance calculated (glycogen deposition minus glycogen to glucose flux). (A) 11-h-fasted subjects; $(B)$ 60-h-fasted subjects.
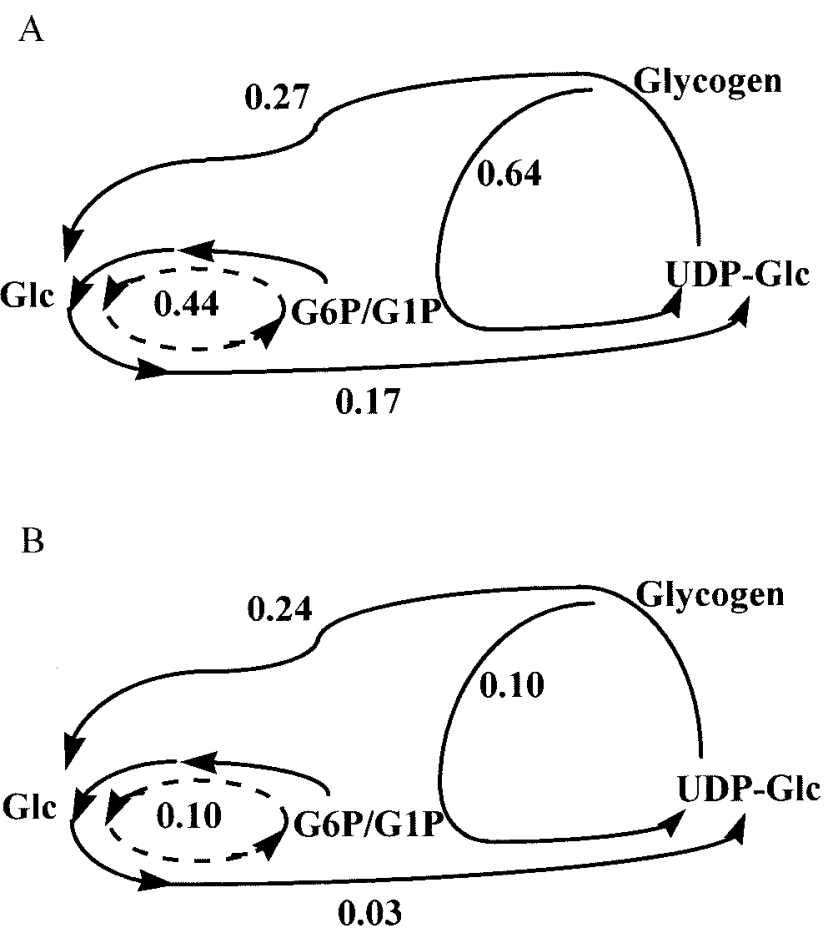

Figure 12. Hepatic cycles in 11 -h- versus 60 -h-fasted subjects. Numbers next to each pathway represent absolute fluxes through cycle. (A) 11-h-fasted subjects; (B) 60-h-fasted subjects.

(Fig. 12). In general, all of these cycles tended to be lower after a prolonged fast than an overnight fast.

\section{Discussion}

Our objective was to measure intracellular carbohydrate metabolic fluxes in humans by the concurrent use of several new techniques (22-33), and to answer the seemingly straightforward question, "Where does blood glucose come from during a fast?" The results demonstrate that carbohydrate metabolism is, in fact, not so straightforward. Cycles of glycogen synthesis and breakdown occur during a fast, so that identifying the ultimate metabolic source of blood glucose is not synonymous with understanding the detailed pathway traversed. This complexity may explain previous contradictions in the literature between net balances $(7,8)$ and isotopic fluxes $(2-6)$.

Several independent aspects of our data support the conclusion that carbon flow through the GNG pathway into glycogen and glycogen turnover are important features of fasting metabolism in humans. First, the GlcUA technique clearly demonstrates that hepatic UDP-GNG occurs to a substantial degree during both overnight and prolonged fasting. The values of $\mathrm{f}_{\mathrm{GlcUA}}$ and $\mathrm{f}_{\mathrm{Glc}}$ were not significantly different in overnight or prolonged fasts. We $(16,23,25,29)$ and Rother and Schwenk $(32,33)$ had previously measured hepatic UDP-glucose turnover by the galactose dilution/GlcUA probe technique in animal models (rats, dogs) and overnight-fasted or glucose-fed humans. Here, we observed that RaUDP-glc was about half of Ra glc in prolonged as well as in overnight-fasted subjects. The Ra UDP-glc approach had not been combined previously with measurement of fractional UDP-GNG to cal- 
culate absolute UDP-GNG flux. Absolute UDP-GNG flux was $0.30-0.40 \mathrm{mg} / \mathrm{kg}$ per body weight per minute under different fasting conditions (Fig. 11).

Second, the measurement of labeled galactose recovery in blood glucose confirmed that the great majority of labeled carbon flux into UDP-glc did not return to the bloodstream. This is the first report of label retention from UDP-glucose in the liver (the tissue presumed to represent most or all of the glucuronidation in humans) $(36,37)$ and is an important addition to the quantitative model (Fig. 3). Retention of labeled galactose was $65-75 \%$ during a $4-6-\mathrm{h}\left[{ }^{2} \mathrm{H}\right]$ galactose infusion and the label was mobilizable by administration of glucagon (Fig. 6). UDP-glc derived from GNG presumably has a similar fate as UDP-glc derived from galactose, so net deposition of glycogen from the GNG pathway must have occurred. Thus, flux through GNG into UDP-glucose represents a quantitative addition flux through the GNG pathway that must be added to flux through GNG into plasma glucose.

Third, the close quantitative congruence of independent measures supports the model proposed here. Retained glyconeogenesis calculated by the GlcUA technique $(\sim 0.31 \mathrm{mg} / \mathrm{kg}$ per minute) in prolonged fasts nearly exactly balanced the persistent flux from unlabeled glycogen to glucose $(\sim 0.32 \mathrm{mg} / \mathrm{kg}$ per minute). These measurements are completely independent: the former from MIDA on GlcUA, dilution of $\left[1-{ }^{2} \mathrm{H}_{1}\right]$ galactose in GlcUA, and recovery of $\left[1-{ }^{2} \mathrm{H}_{1}\right]$ galactose in plasma glucose; the latter from MIDA on plasma glucose and dilution of $\left[\mathrm{U}_{-13} \mathrm{C}_{6}\right]$ glucose in plasma glucose. One expects that after $60 \mathrm{~h}$ of fasting, hepatic glycogen balance should be about zero, which these independent measurements confirm. However, this does not mean that liver glycogen content must be zero or that unidirectional contribution from glycogen to glucose must be zero (Table III).

Fourth, the evidence from prolonged tracer infusion studies also supports the glyconeogenesis/glycogen turnover model. If our estimate that retained glyconeogenesis is $\sim 0.30 \mathrm{mg} / \mathrm{kg}$ per body weight per minute ( $\cong 0.85 \mathrm{mg} / \mathrm{gww}$ per hour) is correct, the $t_{1 / 2}$ of glycogen replacement by GNG-derived glucose after a prolonged fast should be about 4-9 h. Prolongation of $\left[2-{ }^{13} \mathrm{C}_{1}\right]$ glycerol infusions from 4 to $10 \mathrm{~h}$ should therefore result in at least $50 \%$ of the input that was measured as glycogenderived at $4 \mathrm{~h}$ being replaced by GNG-derived glucose by $10 \mathrm{~h}$; $\mathrm{f}_{\mathrm{Glc}}$ should increase proportionately. This is precisely what was observed in subjects infused with $\left[2-{ }^{13} \mathrm{C}_{1}\right]$ glycerol for $10 \mathrm{~h}$ after a prolonged fast (Table IV, Fig. 5). Similar results were observed in overnight fasted subjects as well (Fig. 10), in whom $\mathrm{f}_{\mathrm{Glc}}$ rose steadily, but at a slower rate, congruent with the larger glycogen stores present $\left(t_{1 / 2} \cong 30 \mathrm{~h}\right)$.

Finally, these estimates of glyconeogenesis and glycogen turnover were directly supported by the composition of glycogen mobilized after administration of glucagon after a prolonged tracer infusion. Glucagon is generally believed to increase GP primarily by stimulating glycogenolysis and recent NMR spectroscopic measurements in overnight-fasted humans confirmed that net hepatic glycogenolysis accounted for $>90 \%$ of GP after administration of glucagon (38). The previous administration of $\left[1-{ }^{2} \mathrm{H}_{1}\right]$ galactose allowed us to quantify the precise extent to which glucagon increased glycogen mobilization. GNG-glucose deposited in, and mobilized from, glycogen could then be compared to direct GNG, or GNG flux that did not pass through glycogen. Glucagon administration clearly caused mobilization of glycogen (Fig. 6), based on the large increase in $\left[1-{ }^{2} \mathrm{H}_{1}\right]$ galactose recovery in plasma glucose, and the composition of the glycogen released either before or after glucagon was very close to the values predicted $(\sim 50$ $75 \%$ GNG-labeled, $\sim 25-50 \%$ unlabeled or pre-existing).

We assumed no particular order of glycogen turnover. The model was of random breakdown from a well-mixed glycogen pool, rather than a last in/first out or first in/first out model. Evidence for ordered turnover in liver glycogen $(18,39,40)$ has been generated under conditions of carbohydrate feeding or feeding followed by fasting (i.e., during or after a period of net glycogen accumulation). The physical organization of glycogen synthesis and breakdown during fasting, when synthesis is not in a stimulated state and there is net glycogen depletion, remains unknown. It is possible that different populations of glycogen particles are mobilized and replenished, under conditions of negative or zero hepatic glycogen balance, for example. Our results were consistent with the assumption of no particular order for glycogen turnover, in that roughly half of glycogen appeared to come from GNG-labeled units, under basal conditions and postglucagon (Table IV). It should be pointed out that these calculations about glycogen composition only apply to the labeled glycogen that was retained in the liver during the isotope infusion. Flux from UDP-glc to plasma glucose during the infusion period was measured and accounted for separately (Table III, Fig. 12). The latter form of glycogen cycling represented $20-40 \%$ of UDP-glucose flux; this component of glycogen turnover is indeed ordered (last in/ first out) under nonaccumulating conditions.

An important implication of these results is that the correct value for isotopically measured $\mathrm{f}_{\mathrm{Glc}}$ need not be $100 \%$, and indeed is not $100 \%$, after a prolonged fast, contrary to the common assumption $(2,41)$. In fact, certain techniques used previously for measuring $\mathrm{f}_{\mathrm{Glc}}$ that were reported as being close to $100 \%$ in fasted humans (e.g., the $\left[2{ }^{14} \mathrm{C}\right]$ acetate method of Consoli et al. [2]) have since proven to be flawed (11).

Nevertheless, values of $\mathrm{f}_{\mathrm{Glc}}$ and $\mathrm{f}_{\mathrm{GlcUA}}$ reached $84-96 \%$ after prolonged infusions of $\left[2-{ }^{13} \mathrm{C}_{1}\right]$ glycerol (Fig. 5) confirming MIDA results with $\left[2{ }^{13} \mathrm{C}_{1}\right]$ glycerol in vivo in rats $(16,26,42)$ and mice (our unpublished observations), and in perfused livers from fasted rats (42). The values of $\mathrm{f}_{\mathrm{GlcuA}}$ were not significantly higher than for $\mathrm{f}_{\mathrm{Glc}}$, and values of $\mathrm{p}$ in glucose and GlcUA were not different in paired subjects $(0.121 \pm 0.06$ versus $0.121 \pm 0.010$, Table III). Ekberg et al. (43) reported less efficient labeling from $\left[{ }^{14} \mathrm{C}\right]$ glycerol in GlcUA than plasma glucose, relative to labeling from $\left[{ }^{14} \mathrm{C}\right]$ lactate, but we did not measure labeled lactate incorporation for comparison. The inability of Previs et al. (41) to achieve high values of $f_{\text {Glc }}$ in fasted animals in all likelihood relates to analytic problems perhaps stemming from their use of different tracers (triplelabeled glycerol or lactate) that necessitates use of a different metabolic model and invokes very different analytic problems for the isotopomers monitored. Clearly, there is no problem in achieving values of $\mathrm{f}_{\mathrm{Glc}}$ or $\mathrm{f}_{\mathrm{GlcUA}} \geq 90 \%$ with $\left[2-{ }^{13} \mathrm{C}_{1}\right]$ glycerol, as we show here (Table IV, Fig. 5) and elsewhere (26), and as Peroni et al. also reported (42), when experimental design and analytic techniques are appropriate.

Several methodologic issues deserve consideration. First is the potential impact of contributions by the kidney (9). The fact that the kidney can convert glycerol to glucose works in favor of the technique that we use here: plasma GNG from labeled glycerol is observed, regardless of the tissue source. A problem could arise, in theory, if the isotopic enrichment of 
the triose-phosphate precursor pools in the two tissues were markedly different. In practice, however $(26,31)$, even a substantial difference (e.g., a two- to threefold difference) between the values of $\mathrm{p}$ in the two precursor pools would have a small effect on calculated gluconeogenesis $(<5 \%)$. Another question is, the extent to which urinary glucuronate represents hepatic UDP-glc. The contribution to secreted acetaminophen-GlcUA by the kidneys is believed to be quantitatively minor - i.e., $\sim 5 \%(36,37)$. Thus, urinary GlcUA represents hepatic UDP-glc with a relatively high degree of specificity.

The GlcUA correction factor for calculating total glucose output and glucose cycling $(16,23)$ could also be affected by renal GP. If the direct pathway contribution to UDP-glc is similar in liver and kidney, the correction factor will be correct regardless of contributions to GP by the two tissues. If the direct pathway contribution is different in the two tissues, the impact depends upon the difference between the renal contributions to glucose and GlcUA. The kidney may contribute $10-20 \%$ of GP and $5 \%$ of GlcUA $(9,36,37)$. If so, the total glucose output calculation (equation $12 \mathrm{~B}$, Table II) will be off by $5-15 \%$ of the difference between direct pathways in the two tissues: e.g., if direct contribution is $20 \%$ in liver and $40 \%$ in kidney, the correction will be underestimated by $1-3 \%(5-15 \% \times 20 \%$ difference).

The assumption of UDP-glc/glucose-1-phosphate irreversibility (35) is made in our calculation of glycogen cycling. This assumption is well-founded biochemically. However, our estimates of retained UDP-glc by the liver (i.e., irreversible disposal into UDP-glc) would not be affected even if it were not true, because we measure the fractional recovery of labeled UDP-glc (i.e., of administered $\left[{ }^{2} \mathrm{H}\right]$ galactose) in blood glucose. If more labeled UDP-glc escaped by hydrolysis of UDP-glc, we would measure it. Although the interpretation (glycogen cycling) would be affected, the measured cycling through UDP-glc would remain accurate. Since, in fact, 65$75 \%$ of labeled UDP-glc is retained in liver in fasted subjects, the magnitude of UDP-glc hydrolysis cannot be, in any case, substantial.
A number of inconsistencies in the published literature may be explained by the glyconeogenesis/glycogen turnover model. As noted above, the NMR spectroscopic estimate of the rate of hepatic glycogen loss (7) was about $0.80 \mathrm{mg} / \mathrm{kg}$ per minute (36\% of total GP) after an overnight fast. After correcting for glycogen synthesized and retained in the liver from GNG $(0.30 \mathrm{mg} / \mathrm{kg}$ per minute $)$ and the direct glucose pathway $(0.17 \mathrm{mg} / \mathrm{kg}$ per minute), our estimate of net glycogen depletion rate was similar: $0.93 \mathrm{mg} / \mathrm{kg}$ per minute or $42 \%$ of total $\mathrm{GP}$, instead of $1.40 \mathrm{mg} / \mathrm{kg}$ per minute $(64 \%$ of GP) if we had not included these routes of glycogen synthesis in the calculations. The sources of glucose during fasts of 11- and 60-h duration are shown schematically (Fig. 13). Different measurement approaches measure different components of these fluxes, i.e., traditional isotopic methods measure $\mathrm{f}$ and l-f (left side of figures) while NMR spectroscopy measures net glycogen loss, and neither method alone measures total GNG or total glycogen to glucose fluxes (right side of figures).

The question of where sufficient GNG precursors could come from to account for estimated rates of GNG (8) also does not seem a serious problem with the numbers generated here. The sum of GNG flux plus retained UDP-GNG flux in overnight-fasted subjects was $1.09 \mathrm{mg} / \mathrm{kg}$ per minute (Figs. 8 and 11). A small input from glutamine (44), or slightly more amino acid input (e.g., from labile nitrogen stores, portal amino acids, hepatic or intestinal proteolysis), or some renal GNG (9), if added to the estimated precursor load of $0.60-0.80$ $\mathrm{mg} / \mathrm{kg}$ per minute from the literature on hepatic arteriovenous balances (8), could easily increase the value to about $1.1 \mathrm{mg} / \mathrm{kg}$ per minute. It should be noted that the $\mathrm{f}_{\mathrm{Glc}}$ values observed after prolonged infusions of $\left[2-{ }^{13} \mathrm{C}_{1}\right]$ glycerol were similar to recent values reported with a ${ }^{2} \mathrm{H}_{2} \mathrm{O}$ incorporation technique (4), in which values were measured $9 \mathrm{~h}$ after ${ }^{2} \mathrm{H}_{2} \mathrm{O}$ administration: $\sim 40-45 \%$ by MIDA versus $47 \%$ by ${ }^{2} \mathrm{H}_{2} \mathrm{O}$ in overnight fasted subjects; and $85 \%$ by MIDA versus $93 \%$ by the ${ }^{2} \mathrm{H}_{2} \mathrm{O}$ incorporation method in prolonged fasting. Although it is possible that the ${ }^{2} \mathrm{H}_{2} \mathrm{O}$ method slightly overestimates fractional GNG or the MIDA method slightly underes-

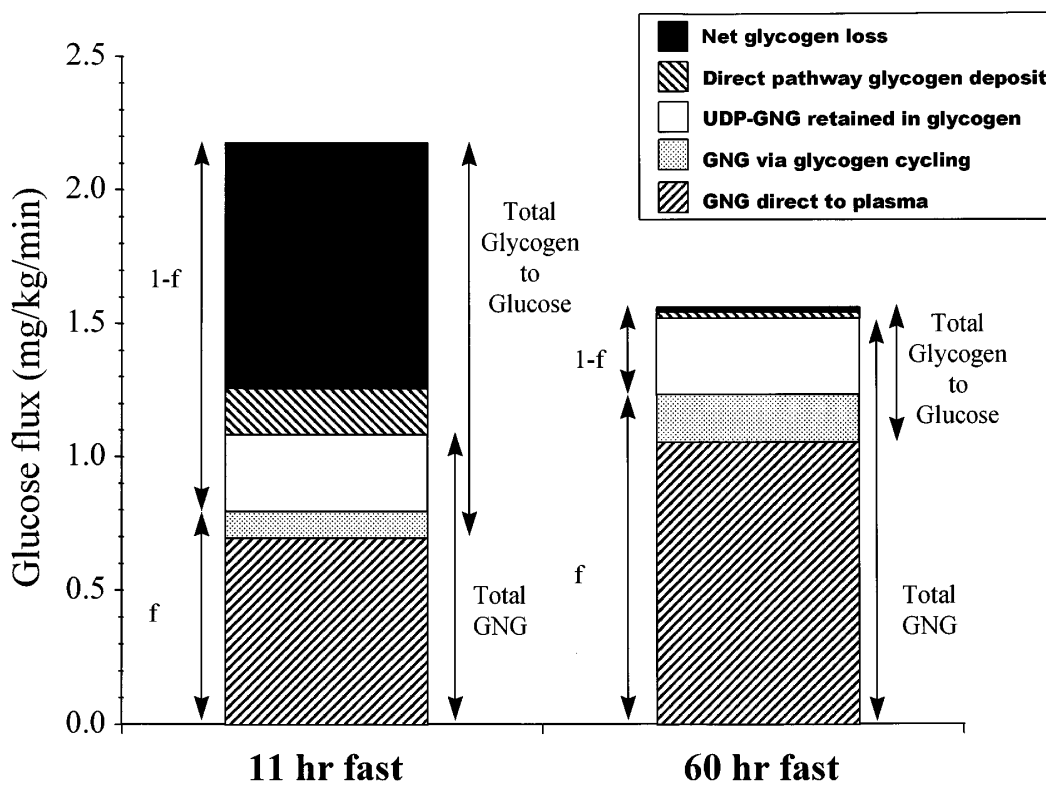

Figure 13. Sources of glucose during fasting of different durations shown schematically. Note overlap between total glycogen to glucose flux and total GNG flux. Results shown for prolonged fast are from subjects $(n=5)$ undergoing complete isotopic paradigm (see text). 
timates fractional GNG, the quantitative differences are not substantial and either method appears to provide similarly accurate estimates of GNG.

The documentation of significant UDP-GNG and glycogen turnover during overnight and prolonged fasting has some interesting physiologic implications. First, the interposition of glycogen as a way station in the pathway of GNG may serve physiologic functions. Maintenance of glycogen stores and through-put permits the rapid mobilization of glycogen, if the need arises during a prolonged fast. Indeed, we found that glucagon administration resulted in mobilization of roughly equal amounts of GNG-derived glucose units that had been recently deposited in glycogen as stimulation of the direct GNG pathway in these ostensibly glycogen-depleted livers. Second, the interposition of the glycogen synthesis/glycogenolysis pathway for a substantial proportion of GNG flux allows for additional loci of metabolic control and, pari passu, for potential sites of metabolic dysregulation. Disorders of excessive or deficient GP could be due to disturbances of this portion of the GNG pathway. For this reason alone, it is important to identify not only the net sources of glucose but also the specific pathways and reactions traversed to produce glucose. Previous indirect evidence (13-16) has suggested that partitioning of GNG flux between glycogen and blood glucose is actively regulated. The capacity to measure the partitioning of GNG flux into both end-products in vivo in humans (Fig. 11) should allow investigation of the physiologic and the pathophysiologic significance of this regulatory branch-point in glucose-producing pathways. Identification of drugs or gene products that act at this node may also have therapeutic implications (12).

In conclusion, several lines of evidence indicate that gluconeogenic flux into glycogen and glycogen turnover persist during overnight as well as prolonged fasting in normal humans. The occurrence of this intrahepatic pathway provides a possible explanation for inconsistencies in the published literature concerning the contributions from GNG versus glycogenolysis to GP. The regulation of hepatic glyconeogenesis and glycogen turnover in conditions such as NIDDM or hypoglycemic disorders can also be studied by use of the techniques described here.

\section{Acknowledgments}

We gratefully acknowledge the nurses in the San Francisco General Hospital GCRC for their help and Cici Hyde for typing the manuscript.

This work was partially funded by a clinical research grant from the American Diabetes Association, National Institutes of Health grant DK40995, a grant from the Nora Eccles Treadwell Foundation, a University of California Faculty Research Grant, and NIH grant RR-00083 from the Division of Research Resources for the General Clinical Research Center.

\section{References}

1. Nilsson, L.H., P. Furst, and E. Hultman. 1973. Carbohydrate metabolism of the liver in normal man under varying dietary conditions. Scand. J. Clin. Lab. Invest. 32:331-337.

2. Consoli, A., F.P. Kennedy, J. Miles, and J.E. Gerich. 1987. Determination of Krebs cycle metabolic carbon exchange in vivo and its use to estimate individual contributions of gluconeogenesis and glycogenolysis to overall glucose output in man. J. Clin. Invest. 80:1303-1310.

3. Landau, B.R., J. Wahren, V. Chandramouli, W.C. Schumann, K. Ekberg, and S.C. Kalhan. 1995. Use of ${ }^{2} \mathrm{H}_{2} \mathrm{O}$ for estimating rates of gluconeogenesis.
Application to the fasted state. J. Clin. Invest. 95:172-178.

4. Landau, B.R., J. Wahren, V. Chandramouli, W.C. Schumann, K. Ekberg, and S.C. Kalhan. 1995. Contributions to gluconeogenesis to glucose production in the fasted state. J. Clin. Invest. 98:378-385.

5. Lee, W.P., S. Bassilian, E.A. Bergner, P. Wals, and J. Katz. 1994. Mass isotopomer study of gluconeogenesis with ${ }^{13} \mathrm{C}$-labeled lactate in man. Clin. Res. 42:28A

6. Hellerstein, M., R. Neese, P. Linfoot, M. Christiansen, and A. Letscher. 1996. Detailed characterization in fasting humans of intrahepatic fluxes through gluconeogenesis (GNG) and glycogen. Diabetes. 45(Suppl. 2):36A.

7. Rothman, D.L., I. Magnusson, L.D. Katz, R.G. Shulman, and G.I. Shulman. 1991. Quantitation of hepatic glycogenolysis and gluconeogenesis in fasting humans with ${ }^{13} \mathrm{C}-\mathrm{NMR}$. Science (Wash. DC). 254:573-576.

8. Barrett, E.J., and Z. Liu. 1993. Hepatic glucose metabolism and insulin resistance in NIDDM and obesity. Bailliere's Clin. Endocrinol. Metab. 7(4): 875-901.

9. Stumvoll, M., U. Chintalapudi, G. Perriello, S. Welle, O. Gutierrez, and J. Gerich. 1995. Uptake and release of glucose by the human kidney. Postabsorptive rates and responses to epinephrine. J. Clin. Invest. 96:2528-2533.

10. Weinman, E.O., E.H. Strisower, and I.L. Chaikoff. 1957. Conversion of fatty acids to carbohydrate: applications of isotopes to this problem and the role of the Krebs cycle as a synthetic pathway. Physiol. Rev. 37: 252-272.

11. Schumann, W.C., I. Magnusson, V. Chandramouli, K. Kumaran, J. Wahren, and B.R. Landau. 1991. Metabolism of $\left[2-{ }^{14} \mathrm{C}\right]$ acetate and its use in assessing hepatic Krebs cycle activity and gluconeogenesis. J. Biol. Chem. 266: 6985-6990.

12. Hellerstein, M.K. 1995. Isotopic studies of carbohydrate metabolism in non-insulin-dependent diabetes mellitus. Curr. Opin. Endocrinol. Diab. 2:518529

13. Shikama, H., and M. Ui. 1978. Glucose load diverts hepatic gluconeogenic product from glucose to glycogen in vivo. Am. J. Physiol. 235:E354-E360.

14. Arion, W.J., A.J. Lange, H.E. Walls, and L.M. Ballas. 1980. Evidence for the participation of independent translocases for phosphate and glucose6-phosphate in the microsomal glucose-6-phosphatase system. J. Biol. Chem. 255:10396-10406

15. Rossetti, L., A. Giaccari, P. Barzilai, K. Howard, G. Sebel, and M. Hu. 1993. Mechanism by which hyperglycemia inhibits glucose production in conscious rats. Implications for the pathophysiology of fasting hyperglycemia in diabetes. J. Clin. Invest. 92:1126-1134.

16. Hellerstein, M.K., R.A. Neese, J.-M. Schwarz, S. Turner, D. Faix, and K. Wu. 1997. Altered fluxes responsible for reduced hepatic glucose production and gluconeogenesis by exogenous glucose in rats. Am. J. Physiol. 272:E163E172.

17. Barrett, E.J., S. Bevilacqua, R.A. DeFronzo, and E. Ferrannini. 1994. Glycogen turnover during refeeding in the post-absorptive dog: implications for the estimation of glycogen formation using tracer methods. Metab. Clin. Exp. 43:285-292.

18. Magnusson, I., D.L. Rothman, B. Jucker, G.W. Cline, R.G. Shulman, and G.I. Shulman. 1994. Liver glycogen turnover in fed and fasted humans. Am. J. Physiol. 266:E796-E803.

19. Jahoor, F., E.J. Peters, and R.R. Wolfe. 1990. The relationship between gluconeogenic substrate supply and glucose production in humans. Am. J. Physiol. 258:E288-E296.

20. Jenssen, T., N. Nurjhan, A. Consoli, and J.E. Gerich. 1990. Failure of substrate induced gluconeogenesis to increase overall glucose appearance without a change in plasma glucose concentration. J. Clin. Invest. 86:489-497.

21. Clore, J.N., and W.G. Blackard. 1994. Suppression of gluconeogenesis after a 3-day fast does not deplete liver glycogen in patients with NIDDM. Diabetes. 43:256-262.

22. Hellerstein, M.K., D.J. Greenblatt, and H.N. Munro. 1986. Glycoconjugates as non-invasive probes of intrahepatic metabolism. The pathway of glucose entry into compartmentalized hepatic UDP-glucose pools during feeding induced glycogen accumulation. Proc. Natl. Acad. Sci. USA. 83:7044-7048.

23. Hellerstein, M.K., S. Kaempfer, J.-M. Schwarz, K. Wu, and C.H.L. Shackleton. 1995. Rate of glucose entry into hepatic UDP-glucose by the direct pathway in fasted and fed states in normal humans. Metab. Clin. Exp. 44(2): 172-182.

24. Shulman, G.I., G. Cline, W.C. Shulman, V. Chandramouli, K. Kumaron, and R.R. Landau. 1990. Quantitative comparison of pathways of hepatic glycogen repletion in fed and fasted humans. Am. J. Physiol. 259:E335-E341.

25. Hellerstein, M.K., A. Letscher, J.-M. Schwarz, D. Cesar, C.H.L. Shackleton, S. Turner, R. Neese, K. Wu, S. Bock, and S. Kaempfer. 1997. Measurement of hepatic Ra UDP-glucose in vivo in rats: relation to glycogen deposition and labeling patterns. Am. J. Physiol. 272:E155-E162.

26. Neese, R.A., J.-M. Schwarz, D. Faix, S.M. Turner, A. Letscher, D. Vu, and M.K. Hellerstein. 1995. Gluconeogenesis and intrahepatic triosphosphate flux in response to fasting or substrate loads. Application of the mass isotopomer distribution analysis technique with testing of assumptions and potential problems. J. Biol. Chem. 270:14452-14463.

27. Neese, R.A., and M.K. Hellerstein. 1995. Appendix. Calculations for gluconeogenesis by mass isotopomer distribution analysis. J. Biol. Chem. 270: 14464-14466. 
28. Dekker, E., M.K. Hellerstein, J.A. Romijn, R.A. Neese, N. Peshu, E. Endert, K. Marsh, and H. Sauerwein. 1997. Glucose homeostasis in children with falciparum malaria: precursor supply limits gluconeogenesis and glucose production. J. Clin. Endocrinol. Metab. In press.

29. Hellerstein, M.K. 1987. In vivo measurement of the appearance rate of hepatic UDP-glucose and partitioning of gluconeogenic flux in fasting and refed rats. Clin. Res. 35:505A.

30. Schwarz, J.-M., R.A. Neese, S. Turner, D. Dare, and M.K. Hellerstein. 1995. Short-term alterations in carbohydrate energy intake in humans: striking effects on hepatic glucose production, de novo lipogenesis, lipolysis and wholebody fuel selection. J. Clin. Invest. 96:2735-2743.

31. Steele, R. 1959. Influences of glucose loading and of injected insulin on hepatic glucose output. Ann. NY Acad. Sci. 82:420-430.

32. Rother, K.I., and W.F. Schwenk. 1995. Hepatic glycogen accurately reflected by acetaminophen-glucuronide in dogs refed after fasting. Am. J. Physiol. 269:766-773.

33. Rother, K.I., and W.F. Schwenk. 1995. Glucose production in glycogen storage disease I is not associated with increased cycling through hepatic glycogen. Am. J. Physiol. 269:774-778.

34. Hellerstein, M.K., and R. Neese. 1992. Mass isotopomer distribution analysis: a technique for measuring biosynthesis and turnover of polymers. Am. J. Physiol. 263:E988-E1001.

35. Lehninger, A.L. 1975. Biochemistry. The molecular basis of cell structure and function. 2nd Ed. Worth Publishers, NY. Pp. 546, 620, 896, 934.

36. Ross, B., J. Tange, K. Emslie, S. Hart, M. Small, I. Calder. 1980. Paracetamol metabolism by the isolated perfused rat kidney. Kidney Int. 18:562-570.
37. Lowenthal, D.T., S. Oie, J.C. Van Stone, W.A. Briggs, G. Levy. 1976. Pharmacokinetics of acetaminophen elimination by anephric patients. J. Pharmacol. Exp. Ther. 196:570-578.

38. Magnusson, I., D.L. Rothman, D.P. Gerard, L.D. Katz, and G.I. Shulman. 1995. Contributions of hepatic glycogenolysis to glucose production in humans in response to a physiologic increase in plasma glucagon concentration. Diabetes. 44:185-189.

39. Henning, S.L., R.B. Wambolt, B.O. Schonekess, G.D. Lopaschuk, and M.F. Allard. 1996. Contribution of glycogen to aerobic myocardial glucose utilization. Circulation. 93(8):1549-1555.

40. Hers, H.G. 1976. The control of glycogen metabolism in the liver. Annu. Rev. Biochem. 45:167-189.

41. Previs, S.F., C.A. Fernandez, D. Yang, M.V. Soloviev, D. France, and H. Brunengraber. 1995. Limitations of the mass isotopomer distribution analysis of glucose to study gluconeogenesis substrate cycling between glycerol and triose phosphates in liver. J. Biol. Chem. 270:19806-19815.

42. Peroni, O., V. Large, and M. Beylot. 1995. Measuring gluconeogenesis with $\left[2-{ }^{13} \mathrm{C}\right]$ glycerol and mass isotopomer distribution analysis of glucose. $\mathrm{Am}$. J. Physiol. 269:E516-E523.

43. Ekberg, K., V. Chandramouli, K. Kumaran, W.C. Schuman, J. Wahren, and B.R. Landau. 1995. Gluconeogenesis and glucuronidation in liver in vivo and the heterogeneity of hepatocyte function. J. Biol. Chem. 270:21715-21717.

44. Nurjhan, N., A. Bucci, G. Perriello, M. Stumvoll, G. Dailey, D.M. Bier, I. Toft, T.G. Jenssen, and J.E. Gerich. 1995. Glutamine: a major gluconeogenic precursor and vehicle for interorgan carbon transport in man. J. Clin. Invest. 95 272-277. 